\title{
Los obstáculos de una demanda civil de responsabilidad transnacional por violación de derechos humanos: desde la perspectiva del titular del derecho
}

\author{
Legal Barriers to Transnational Civil Liability Claims for Business- \\ Related Human Rights Abuses: a Rightsholder's Approach
}

\author{
Maria Font-Mas \\ Universitat Rovira i Virgili \\ maria.font@urv.cat
}

Sumario: I. La acción civil transnacional contra multinacionales por violación de derechos humanos.-II. Presentación del ejemplolitigio «Akpan \& Milieudefensie v. Shell Nigeria \& Netherlands». - III. Obstáculos y dificultades procesales en el litigio transnacional. 1. La determinación de la competencia judicial internacional de los tribunales del domicilio de la matriz de un Estado miembro de la UE. 2. Competencia territorial, presentación de la demanda, representación y tasas judiciales. 3. Lengua del proceso judicial. 4. Capacidad para ser parte (legitimación procesal), la legitimación (material) y subrogación: el papel de las ONGs. 5. Plazos de caducidad y/o prescripción. 6. Ley aplicable al fondo. 7. Prueba del derecho extranjero. 8. La carga y aportación de pruebas y su valor probatorio. 9. Sentencia, apelación y ejecución forzosa.-IV. Costes del litigio, costas, asistencia jurídica gratuita. $-V$. Reflexiones finales.

Resumen: El objeto del presente estudio se focaliza en los procesos civiles internacionales en materia de responsabilidad empresarial por abusos de los derechos humanos. Desgranamos cronológicamente las fases del proceso ejemplificándolas a través de un caso muy conocido (Akpan contra Shell) en el que fue competente un tribunal de un Estado miembro de la UE (Países Bajos) respecto de los daños sufridos en un tercer Estado (Nigeria). Exponemos las principales trabas jurídicas en este tipo de litigio, desde la interposición de la demanda, pasando por la lengua del proceso, hasta plantear una hipotética ejecución transnacional de la sentencia neerlandesa en Nigeria. Ello con una doble finalidad, por un lado, proporcionar desde la perspectiva del titular del derecho en este tipo de procesos (víctimas y ONGs) información previa para poder planificar y advertir las dificultades jurídicas que plantea una demanda transnacional por daños contra una multinacional. Por otro lado, para evidenciar la desigualdad existente 
entre las partes en litigio desde el punto de vista económico y procesal, alentando a que las normas internas e internacionales cumplan con los derechos fundamentales a un proceso equitativo y a la tutela judicial efectiva (art. $6 \mathrm{CEDH}$ y art. 47 CDFUE) en este tipo de litigios.

Palabras clave: Demanda civil de responsabilidad transnacional, derechos humanos y empresas, derecho a un proceso equitativo

Abstract: The article sets out to identify key barriers that rightsholders face when bringing a business human rights claim against a corporate opponent. It points out each barrier with an illustration from the Akpan \& Milieudefensie $v$. Shell Nigeria \& Netherlands case. It presents the main legal obstacles in this type of litigation, such as the filing of the lawsuit, the language of the process, a hypothetical transnational execution of the Dutch judgement in Nigeria. It has a double purpose, namely, to provide the rightsholders in this sort of process (victims and NGOs) information about legal difficulties caused by a transnational claim for damages against a multinational corporation. As well as to confirm the inequality between the parties from the economic and procedural point of view, encouraging the fulfillment of the fundamental rights to a fair trial and right to an effective remedy (art. 6 ECHR and art. 47 CFREU).

Keywords: transnational civil liability claims, human rights \& business, right to a fair trial

\section{La acción civil transnacional contra multinacionales por violación de derechos humanos}

Las vulneraciones de los derechos humanos perpetrados por empresas transnacionales en todo el mundo, a través de sus filiales, socios comerciales o subcontratantes es, desafortunadamente, una realidad ${ }^{1}$. Ello, a pesar de los tímidos avances en las políticas legislativas nacionales, y la creciente sensibilización internacional por parte de la ONU y organizaciones internacionales públicas y privadas, que dictan directrices para precaver los abusos. Ante esta situación, y mientras no se eviten las violaciones de derechos humanos por parte de las empresas a través medidas legislativas preventivas (proteger) y la implicación de las empresas en el deber de vi-

${ }^{1}$ Indicamos solo una de las plataformas dónde pueden encontrarse las denuncias de prácticas de violación de derechos humanos perpetradas por empresas multinacionales, en concreto, el «Business \& Human Rights Resource Centre»: https://www.business-humanrights. org/es\#, acceso en enero de 2020. 
gilancia (respetar), sólo queda la posibilidad de tomar medidas correctivas (remediar) ${ }^{2}$.

Efectivamente, las víctimas de las violaciones de derechos humanos pueden denunciar a las empresas generadoras de las vulneraciones por varias vías: como es en el ámbito penal ${ }^{3}$ o en el ámbito administrativo ${ }^{4}$ ante los tribunales del país donde se ha desarrollado la violación de derechos humanos, o bien, buscar un arreglo de la controversia a través de un mecanismo extrajudicial ante instancias supranacionales. Recientemente (diciembre 2019), se han presentado las «Normas de arbitraje de La Haya sobre Derechos humanos y empresa (The Hague Rules)» que prevén un mecanismo nuevo y flexible para resolver disputas de forma consensuada $^{5}$.

Asimismo, puede interponerse una demanda por responsabilidad civil en la que se solicite judicialmente indemnizaciones por los daños sufridos ante la jurisdicción civil de un Estado, sea el Estado del territorio donde se ha producido el daño, o bien ante los tribunales donde tiene el domicilio la empresa multinacional, esta última es la vía que analizamos en el presente estudio.

Antes, debemos advertir, que la acción civil transnacional contra una multinacional por violación de derechos humanos no es la solución, ya que, de conseguirse una sentencia favorable para las víctimas, ello no es óbice

${ }^{2}$ Hacemos referencia a los Principios Rectores Ruggie: «Principios rectores sobre las empresas y los derechos humanos: puesta en práctica del marco de las Naciones Unidas para "proteger, respetar y remediar"» (2011), que fueron elaborados por el Respresentante Especial del Secretariado General (John Ruggie) para la cuestión de los derechos humanos y las empresas transnacionales y otras empresas.

${ }^{3}$ La Corte Penal Internacional carece de jurisdicción sobre las empresas; por ello, solo podrían ser denunciadas en los foros estatales cuando su actuación esté tipificada como responsabilidad penal. Un ejemplo de la lentitud y dificultad de la vía penal es el caso Bhopal (1984) que conoció la justicia india, la cual reconoció la perpetración de delitos graves. A pesar de la sentencia condenatoria, todavía están abiertos los procesos penales mientras aumenta el número de víctimas, sin que se ejecuten las reparaciones. José Elías Esteve Moltó, «The impunity veil of transnational corporations: the judicial saga of Bhopal», en: Empresas y Derechos humanos, coord. por Maria Chiara Marullo y Francisco Javier Zamora Cabot (Nápoles: Ed. Scientifica srl, 2018), esp. 249-276.

${ }^{4}$ A través de sanciones pecuniarias, que en ámbito medioambiental está más extendido legislativamente por contemplar la regla de que quién contamina paga. En otros ámbitos, por ejemplo, el laboral, y teniendo en cuenta el ámbito internacional al que nos referimos, una posible vía de sanción sería la aplicación de las normas imperativas o de policía, cuando existieran.

5 The Hague Rules On Business and Human Rights Arbitration, Center for International Legal Cooperation, The Hague, December 2019: https:/www.cilc.nl/cms/wp-content/ uploads/2019/12/The-Hague-Rules-on-Business-and-Human-Rights-Arbitration_CILC-digital-version.pdf. Acceso en enero de 2020. 
para que las empresas multinacionales cesen sus actividades abusivas en ese mismo territorio o en otro.

El punto de partida de la acción civil son las violaciones de derechos humanos, pero necesariamente adaptadas a las figuras de derecho privado, en concreto, en la esfera de la responsabilidad civil por daños extracontractuales. Debe realizarse el arduo ejercicio de calificación y subsumir violaciones de derechos humanos, como sería la esclavitud, el desplazamiento de personas, desastres medioambientales, la tortura, etc., en figuras civiles como la detención ilegal, daños personales o patrimoniales, obligaciones extracontractuales. Como indica M. Requejo Isidro, no puede reprobarse a las legislaciones nacionales las deficiencias en este ámbito en materia de responsabilidad civil, ya que dichas normas no han sido concebidas para ser aplicadas en la esfera de la defensa de los derechos humanos. De forma clara sintetiza la misma autora: «estamos ante una litigación civil en la que los derechos humanos son objeto de la acción de forma indirecta: ellos (DDHH) son el verdadero propósito del litigio, pero se reivindican a través de otras categorías». ${ }^{6}$

El análisis que proponemos en este estudio, tiene por objeto los obstáculos jurídico-económicos que surgen en el proceso civil transnacional por daños en que las víctimas reclaman responsabilidad civil en los supuestos en que la matriz de la multinacional se encuentra radicada en un Estado miembro de la Unión Europea (UE). A tal efecto, la razón del presente estudio estriba en la necesidad de informar y prever a las víctimas, sociedad civil y organizaciones no gubernamentales (ONGs) de la existencia de estas trabas u obstáculos jurídicos, en orden a que les permita valorar la conveniencia o no de interponer dicha demanda o, como mínimo, conocer con anticipación, a qué largo, costoso y exasperante proceso judicial se enfrentan. Las dificultades que se apuntan ya se prevén en los Principios Rectores de la ONU de 2011, en concreto el 26, sobre los mecanismos judiciales estatales en que se compele a los Estados a adoptar las medidas apropiadas para asegurar la eficacia de dichos mecanismos, en particular «limitar los obstáculos legales, prácticos y de otros tipos que puedan conducir a una denegación del acceso los mecanismos de reparación».

Destacamos, a priori, una primera constatación que no por obvia no merece ser reiterada, y es que un obstáculo omnipresente durante todo el proceso judicial es el desequilibrio de fuerzas existente entre las partes confrontadas. El poder económico y la influencia política de las

${ }^{6}$ Marta Requejo Isidro, «La responsabilidad de las empresas por violación de derechos humanos deficiencias del marco legal», Scientia Juris (2011), 27. https://www.revuegeneraledudroit.eu/wp-content/uploads/scientia01 theme_requejo.pdf. Acceso en enero de 2020. 
grandes corporaciones mercantiles es correlativo con los recursos financieros de los que disponen y, consecuentemente, el asesoramiento jurídico y el acceso a la información es ingente para las multinacionales mientras que, para las víctimas, sociedad civil y ONGs resulta, por lo general, más limitado. Lo describe L.F.H. Enneking en términos de desigualdad existente entre la demandante del país del daño (violación) y la demandada empresa, en lo que respecta al alcance financiero, el nivel de organización y el acceso a la información relevante de que dispone la empresa ${ }^{7}$. En relación al caso Lago Agrio, M. Requejo Isidro llega a la conclusión desalentadora, si bien realista: «(...) Los demandantes en Ecuador gozaron en varios foros del beneficio de la justicia gratuita; también tuvieron acceso a financiación por parte de terceros. Con ello se puede considerar salvado el desequilibrio de fuerzas que habitualmente se percibe entre las partes activa y pasiva en los litigios similares al presente. Así las cosas, la verdadera asimetría deriva de la protección procesal incrementada de que goza el inversor extranjero, en un marco donde además el derecho de sociedades opera también a su favor. Dos datos que son habituales en el panorama de los movimientos económicos transfronterizos.» 8

En este contexto, las víctimas, sociedad civil y ONGs tendrán que plantearse previamente a la interposición de la demanda, por un lado, las repercusiones personales y sociales, y, por otro, las dificultades jurídicas y económicas de llevar a término la acción judicial.

Así, en cuanto las repercusiones personales y sociales que podrían sufrir las víctimas y quiénes demanden y se oponen a la explotación económica de una multinacional en un territorio, son la propia integridad física, su seguridad o la de sus familiares, o la de sus vecinos ${ }^{9}$. Además, debería asumirse que en una demanda de responsabilidad civil sólo se re-

${ }^{7}$ Liesbeth F.H. Enneking, «Multinationals and Transparency in Foreign Direct Liability Cases», The Dovenschmidt Quarterly, n. ${ }^{\circ} 3$ (2013), 135.

${ }^{8}$ Marta Requejo Isidro, «El Caso Lago Agrio. Multipolaridad en la litigación civil internacional», Revista Catalana de Dret Ambiental 5, n. ${ }^{\circ} 1$ (2014): 25. Acceso en enero 2020: https://revistes.urv.cat/index.php/rcda/article/view/1440.

${ }^{9}$ En los movimientos populares de denuncias a las multinacionales en el área del medio ambiente son innumerables los asesinatos de defensores/as ambientales. Se contabilizaron 321 personas defensoras de derechos humanos asesinadas en 27 países en 2018 de las cuales 247 defendían la tierra, los derechos de los pueblos indígenas y el medio ambiente. En Colombia y México se produjeron el 54\% del total de asesinatos. Datos extraídos de: Antoni Pigrau Solé, «Los mecanismos nacionales de protección de las personas defensoras del medio ambiente en América Latina: avances y limitaciones» (Conferencia, VIII congreso nacional derecho ambiental (vulneración ambiental). Congreso homenaje a Ramón Martín Mateo, Universidad de Sevilla, septiembre 2019) (pendiente de publicación). 
clama una compensación económica, de modo que no es una causa penal y no habrá una sentencia que condene a ningún responsable por delito. Así mismo, tal y como se ha reiterado, de obtener una sentencia favorable a las pretensiones de resarcimiento del daño y al cese de la actividad dañosa, ello no garantizará la no repetición de las actuaciones dañosas de las empresas.

Es imprescindible también advertir que el proceso civil transnacional será extremadamente largo, de ahí la necesidad del apoyo comprometido de la sociedad del entorno donde se ha cometido la violación de derechos humanos, normalmente vehiculada, en el mejor de los casos, a través de una o varias asociaciones o fundaciones, ello es ONGs nacionales del país dónde se ha sufrido el daño; pero también es imprescindible en las demandas transnacionales en esta área la ayuda y el compromiso de las ONGs del país del tribunal donde se interponga la demanda, normalmente, donde radica la matriz de la empresa multinacional.

Por otro lado, deberían plantearse las dificultades jurídicas y económicas que surgen en un litigio transnacional de estas características, que desarrollaremos en los siguientes apartados. La intención es ofrecer información, de forma clara, para que las víctimas y las ONGs demandantes, puedan conocer las características básicas del proceso transnacional y sospesar las dificultades y aspectos jurídico-económicos antes de interponer una demanda civil ante un foro europeo e intentar valorar la viabilidad de sustentar jurídica y económicamente el proceso. $\mathrm{O}$ bien, valorar otras posibilidades, como litigar ante los tribunales de su país, es decir, en el foro donde se ha cometido el daño por parte de la filial, asumiendo las limitaciones que ello supone ${ }^{10}$; o sugerir un arbitraje internacional, o bien, plantear una mediación a los puntos nacionales de contacto $(\mathrm{PCN})^{11}$. Estas alternativas al proceso civil internacional o complemen-

${ }^{10}$ La ONG Milieudefensie responde porque los agricultores no interpusieron la demanda ante los tribunales nigerianos: «Two of them did bring their cases to a Nigerian court but the legal processes in their own country are lengthy and not transparent, so Shell Nigeria is able to constantly intervene in the process. In Nigeria, there are many options for multinationals with sufficient funds to hire expensive lawyers to delay legal proceedings indefinitely. Moreover, our plaintiffs have more faith in the independence of the courts in the Netherlands and therefore in a fair trial.» https://en.milieudefensie.nl/shell-in-nigeria/frequently-asked-questions\#8--why-haven-t-the-plaintiffs-brought-their-cases-to-the-nigerian-court. Acceso en enero 2020.

${ }^{11}$ En seno de la OCDE (Organización para la Cooperación y el Desarrollo Económicos) se han elaborado las «Líneas Directrices de la OCDE para Empresas Multinacionales» (revisión 2011) que prevé un singular mecanismo de implementación, los Puntos Nacionales de Contacto (PNC), que son organismos constituidos por los gobiernos de los países adherentes con el fin de promover e implementar las Directrices. Pero también constituyen «una plataforma de mediación y conciliación para resolver los problemas prácticos que puedan plantearse»: http://www.oecd.org/daf/inv/mne/MNEguidelinesESPANOL.pdf 
tarias, si bien pueden superar algunos obstáculos importantes como es la lentitud en la obtención de una resolución, no tienen por qué suponerse más satisfactorias ${ }^{12}$.

\section{Presentación del ejemplo-litigio «Akpan \& Milieudefensie v. Shell Nigeria \& Netherlands»}

\section{Litigio-ejemplo: Akpan \& Milieudefensie v. Shell Nigeria \& Netherlands $\rightarrow$ presentación del caso}

Cuatro agricultores y pescadores nigerianos demandan a la petrolera Shell, en concreto a Shell petroleum development company of Nigeria LTD (filial de Shell en Nigeria) y a Royal Dutch Shell PLC (matriz neerlandesa de $S h e l l$ ), por los daños causados a las tierras y a los lagos, por derrames de petróleo ocasionados por el sabotaje de las tuberías de las instalaciones de la filial nigeriana, en el territorio del Delta de Nigeria, en concreto, en las poblaciones de Goi, Oruma e Ikot Ada Udo.

Los derrames de petróleo contaminaron las tierras de los agricultores de modo que se destruyó su medio de vida. «Goi es ahora una ciudad fantasma; muy pocos de sus habitantes se han quedado. (...). El olor de la zona es insoportable, el agua potable está contaminada, los peces han muerto y el agua está tan contaminada que no crece nada cerca. El petróleo continúa vertiéndose en la tierra y Shell no se ha molestado a actualizar sus gaseoductos oxidados ni a intentar aumentar la seguridad alrededor de las tuberías para protegerlas de los sabotajes.» Milieudefensie calcula que los derrames continuos afectan a 30 millones de personas ${ }^{13}$.

Los cuatro agricultores nigerianos presentaron demanda civil contra la filial nigeriana de Shell y contra la matriz neerlandesa de Shell ante los tribunales ordinarios de los Países Bajos. Junto a estos demandantes, la ONG neerlandesa Milieudefensie [Amigos de la Tierra Países Bajos] es codemandante.

La demanda tiene como pretensiones centrales: la limpieza de los derrames de petróleo, indemnizaciones para los agricultores y que Shell realice las obras de mantenimiento necesarias para evitar futuros derrames.

12 De las alternativas existentes, no hay una óptima, y puede desencadenar una fragmentación de la tutela, véase el ejemplo del caso Lago Agrio en que se iniciaron tres vías distintas de resolución: Marta Requejo Isidro, «El Caso Lago Agrio. Multipolaridad en la litigación civil internacional», Revista Catalana de Dret Ambiental, vol. 5, n. ${ }^{\circ} 1$ (2014). Acceso en enero 2020: https://revistes.urv.cat/index.php/rcda/article/view/1440.

$13 \mathrm{https}$ ://en.milieudefensie.nl/shell-in-nigeria/frequently-asked-questions, acceso en enero de 2020. 
El tribunal del distrito de La Haya (Países Bajos) resolvió y estimó parcialmente una de las demandas el 30 de enero de 2013 (caso AkpanShell); las otras causas fueron desestimas. La sentencia fue recurrida por ambas partes.

El fundamento de nuestro trabajo sigue los parámetros que ya tuvimos la oportunidad de exponer en el estudio: «Derechos humanos y empresas europeas. Un manual práctico para las organizaciones de la sociedad civil y los defensores de los derechos humanos» (2016), en adelante el Manual práctico $2016^{14}$, y que seguiremos, en parte, como hilo conductor. La voluntad del presente trabajo es subsumir, en la medida de lo posible, los obstáculos jurídicos desgranados en dicho Manual práctico 2016, en un ejemplo de demanda civil internacional paradigmático y muy conocido entre la doctrina y los movimientos sociales, en concreto, el caso Akpan contra Shell (Nigeria).

En este asunto se presentaron cuatro demandas por parte de cuatro agricultores y pescadores residentes y nacionales de Nigeria, víctimas de daños ocasionados por la explotación del oleoducto de la petrolera Shell en el Delta de Nigeria. Estas demandas contaban como codemandantes con la ONG neerlandesa Milieudefensie [defensa ambiental]. Los demandados eran la empresa petrolera multinacional Shell, tanto la filial nigeriana como la matriz europea, ante los tribunales de los Países Bajos, en 2008. En 2013 el tribunal del distrito de La Haya (Países Bajos) dictó sentencia ${ }^{15}$, que servirá de ejemplo en este estudio, en la cual se estimaba parcialmente las pretensiones del agricultor Akpan. Las otras causas fueron desestimadas. Pero el caso Akpan aún está vivo, debido a que la sentencia fue recurrida por ambas partes de modo que aun está pendiente la resolución de la apelación por parte del alto tribunal neerlandés.

En aras de desgranar las distintas cuestiones jurídicas del litigio-ejemplo que utilizamos, emplearemos, además del citado Manual práctico 2016 , algunos estudios doctrinales sobre el caso, que son innumerables, de en-

14 Antoni Pigrau; Maria Álvarez; Antonio Cardesa; Maria Font; Daniel Iglesias; Jordi Jaria, Derechos humanos y empresas europeas. Un manual práctico para las organizaciones de la sociedad civil y los defensores de los derechos humanos, 2016: http://humanrightsinbusiness.eu/wp-content/uploads/2016/09/DERECHOS_HUMANOS_Y_EMPRESAS_EUROPEAS_ES.pdf (disponible también en: inglés, francés, portugués), acceso en enero de 2020.

${ }_{15}$ District Court of The Hague, c. C/09/337050/ HA ZA 09-1580, Judgment 30 January 2013, Friday Alfred Akpan \& Milieudefensie, c. Royal Dutch Shell, PLC \& Shell Petroleum Development Company of Nigeria: ECLI:NL:RBDHA:2013:BY9854 Rechtbank Den Haag, 30-01-2013, C/09/337050 / HA ZA 09-1580. Esta sentencia es un ejemplo ideal para ir desgranando los obstáculos procesales que se suceden de forma lineal, sin profundizar en especial en ninguno de ellos, ya que se pretende ofrecer una visión global, aunque inacabada, de una demanda transnacional de responsabilidad por daños. 
tre los que destacamos el de L. García Álvarez ${ }^{16}$ y el de L.F.H. Enneking ${ }^{17}$; también utilizaremos información del portal de la ONG Milieudefensie ${ }^{18}$; noticias y comentarios ${ }^{19}$; la traducción de la legislación neerlandesa ${ }^{20}$ y las fichas de derecho comparado del portal de justicia de la UE, en concreto la Red Judicial Europea ${ }^{21}$.

\section{Obstáculos y dificultades procesales en el litigio transnacional}

Antes de abordar en detalle algunos de los obstáculos procesales que se suceden en un litigio internacional en este concreto ámbito, primero es necesario diferenciar las cuestiones consideradas procesales de las cuestiones calificadas como sustantivas. Dependiendo de tal calificación, se aplicará el derecho procesal del foro (lex fori regit processum) o bien la ley rectora de la relación jurídica (lex causae).

Hay un cierto consenso en considerar como cuestiones procesales: la competencia judicial, las condiciones para la apertura procesal y el sistema de recursos, el desarrollo del proceso y de la vista, la prueba de los hechos y las costas. Y, considerar como cuestiones sustantivas, por lo tanto, vinculadas a la ley rectora que resulte aplicable al fondo del asunto, la legitimación o las presunciones legales 22 .

Sin embargo, hay cuestiones que se califican de uno u otro modo según el sistema jurídico o la norma de origen europeo que la prevea, tal y como sucede en relación a la prescripción o la caducidad.

Presentamos a continuación algunos de los obstáculos propios en los procedimientos transnacionales de forma cronológica al desarrollo del proceso ejemplo (Akpan v. Shell), utilizando para ello la legislación neerlandesa o a la nigeriana según cuál sea el derecho aplicable (procesal o sustantivo) y aplicando o descartando la aplicación de los Reglamentos europeos. Seguidamente indicaremos brevemente la cuestión jurídica en ámbito de Derecho internacio-

${ }^{16}$ Laura García Álvarez, «Daños privados por contaminación en el tráfico externo: a propósito del caso Akpan vs. Shell (Nigeria)», Cuadernos de Derecho Transnacional 5, n. 2 (2013): 548-583. Acceso en enero de 2020, https://e-revistas.uc3m.es/index.php/CDT/article/view/1823.

${ }^{17}$ Liesbeth F.H. Enneking, «The future of Foreign Direct Liability? Exploring the International Relevance of the Dutch Shell Nigeria Case», Utrecht Law Review, 10-1 (2014): 44-54.

${ }_{18}$ Milieudefensie: https://en.milieudefensie.nl/, acceso en enero de 2020.

${ }_{19}$ Una selección puede encontrarse en: https://www.business-humanrights.org/en/shelllawsuit-re-oil-pollution-in-nigeria. Acceso en enero de 2020.

${ }^{20}$ Disponible en: http://www.dutchcivillaw.com, acceso en enero de 2020. Básicamente el Dutch Code of Civil Procedure (DCCP) y el Dutch Civil Code (DCC).

${ }^{21}$ Portal europeo de e-justicia: https://e-justice.europa.eu/home.do, acceso en enero de 2020.

22 Pilar Jiménez Blanco, El proceso civil transfronterizo, (Madrid: Col. Abogacía internacional, 2016), Vol. IV, 22. 
nal privado europeo, en ocasiones no aplicable o existente, por ello atenderemos a las características de las normas estatales de los Estados miembros.

\section{La determinación de la competencia judicial internacional de los tribunales del domicilio de la matriz de un Estado miembro de la UE}

\section{Litigio-ejemplo: Akpan \& Milieudefensie v. Shell Nigeria \& Netherlands $\rightarrow$ Shell como multinacional}

En el caso, es una sociedad domiciliada en Nigeria la que comete el daño y a pesar de formar parte del grupo societario con la matriz domiciliada en la UE, son personas jurídicas independientes. Los demandantes (víctimas y ONG) no pudieron probar la dependencia de la filial con la matriz en la toma de decisiones y con ello la responsabilidad de la matriz. A pesar de que se alegó como precedente la doctrina Chandler v Cape (vid. nota 24), el tribunal estimó que no era aplicable por no ser supuestos similares y no cumplir el test de relación entre la matriz y la filial (FJ 4.32-34) (Vid.ep. III.8 y III.9).

Como cuestión previa a la determinación del foro competente, es preciso conocer la estructura y organización de la empresa multinacional a demandar, con la finalidad de determinar qué conexión hay entre las empresas que conforman el grupo societario, y el nivel de control directo o indirecto que ejerce la empresa matriz respeto a las otras empresas que conforman el grupo. La conexión viene fijada legalmente y de esta puede determinarse la responsabilidad separada entre ellas por considerarse personas jurídicas independientes ${ }^{23}$, o bien, podría considerarse que hay de-

${ }^{23}$ El objetivo es responsabilizar la matriz por los daños y que responda con su patrimonio; aunque lo óptimo sería demandar la filial que ha cometido directamente el daño, ante el tribunal del territorio donde se ha cometido el daño y aplicarse el derecho de dicho país donde residen las víctimas, y responder, en su caso, con el patrimonio de la filial. Pero esta segunda posibilidad no es la deseable de momento y en algunos Estados, por falta de garantías judiciales en el proceso en ese país donde radica la filial. Las políticas de promoción y recepción de capital extranjero para la explotación industrial de determinados países, favorecen las prácticas de dichas vulneraciones. Por ejemplo, en México, la inacción del Estado en la esfera de los derechos humanos, ha propiciado la conducta ventajosa de las empresas a causa de la ausencia de transparencia y rendición de cuentas, incremento de la corrupción y la impunidad. Jessica Cristina Romero Michel y Arianna Sánchez Espinosa, «La función social de la empresa en la esfera de los derechos humanos. El panorama actual en México», en: Empresas y Derechos humanos, coord. por Maria Chiara Marullo y Francisco Javier Zamora Cabot (Nápoles: Ed. Scientifica srl, 2018), 181-203. Vid. José Luís Iriarte Ángel, «Empresas multinacionales y derechos humanos. Un análisis reciente desde la perspectiva española», en: Empresas y Derechos humanos, coord. por Maria Chiara Marullo y Francisco Javier Zamora Cabot (Nápoles: Ed. Scientifica srl, 2018), 91-114. 
pendencia, por ejemplo, en la toma de decisiones comunes (u otros criterios) a través de la teoría del levantamiento del velo corporativo. Ello posibilita imputar la responsabilidad a la matriz porque existe prueba de su ejercicio abusivo o fraudulento de la personalidad jurídica. Pero resulta sumamente difícil o imposible examinar (y probar por la actora, que es la demandante-víctima) las relaciones de dependencia entre las empresas que forman un grupo societario, y con ello imputar la responsabilidad a la empresa matriz que es quien toma las decisiones y recibe los beneficios. Consecuentemente, el contexto normativo actual facilita la separación de la personalidad jurídica, y solo la prueba a contrario podría vincular el daño a la matriz que se encuentra en otro Estado y que no ha cometido directamente el daño, ello sería probar que la empresa matriz tenía conocimiento preciso de las actividades de la empresa filial y que ejercía un control efectivo sobre esta ${ }^{24}$.

La determinación de la competencia judicial internacional constituye el primer gran obstáculo al que debe afrontarse el demandante (parte actora) y que condicionará la articulación del resto de aspectos del proceso internacional (ley aplicable, derecho procesal aplicable, cooperación judicial internacional, reconocimiento y ejecución de sentencias, etc.).

La gran dificultad radica en determinar el alcance de la conexión del daño (violación de DDHH) con el foro del Estado dónde se encuentra la empresa matriz, cuando el territorio donde se ha cometido el daño es el del Estado dónde se encuentra la filial ${ }^{25}$. Debe resolverse si los tribunales de los Estados europeos dónde se hallan las sedes de las matrices están legitima-

${ }^{24}$ El ejemplo más conocido en el ámbito del presente estudio es el caso Chandler contra Cape, PLC (2012) EWCA Civ 525, resuelto por los tribunales ingleses, en relación a los daños de salud de los trabajadores de la filial, estableciendo tres criterios de relación entre la empresa matriz y la filial y los daños causados. La sentencia fue muy relevante porque señaló la existencia del deber de cuidado por parte de la empresa matriz de un grupo corporativo cuando se vulneran derechos fundamentales de los empleados de sus filiales.

25 Presentamos los aspectos jurídicos que entablan dicha cuestión de forma resumida por haber sido estudiado en profundidad por otros autores a los que nos remitimos. Laura García Álvarez y Daniel Iglesias Márquez, «La regla de la ubicuidad y la responsabilidad corporativa», en: Empresas y Derechos humanos, coord. por Maria Chiara Marullo y Francisco Javier Zamora Cabot (Nápoles: Ed. Scientifica srl, 2018), 115-156. Daniel Augenstein y Nicola Jägers, «Judicial remedies: The issue of jurisdiction», en: Human Rights in Business. Removal of Barriers to Access to Justice in the European Union, eds. por Juan José Álvarez Rubio; Katerina Yiannibas, (London \& New York: Routledge, 2017) 7-37; Laura García Álvarez, Competencia judicial internacional, daños ambientales y grupos transnacionales de sociedades, (Granada: Ed. Comares 2016); Maria Álvarez Torné, «El Derecho internacional privado ente las vulneraciones de derechos humanos cometidas por empresas y respuestas en la UE», REDI 67, n 2 (2015): 291-296; Marta Requejo Isidro, «Litigación civil internacional por abusos contra Derechos Humanos. El problema de la competencia judicial internacional», $A E$ DIPr 10 (2010): 259-300. 
dos para extender su jurisdicción, es decir, conocer y resolver las controversias acaecidas en terceros Estados. De ser así, ello supondría un ejercicio de la jurisdicción extraterritorial, contrario a las normas de soberanía y no intervención ${ }^{26}$.

Litigio-ejemplo: Akpan \& Milieudefensie v. Shell Nigeria \& Netherlands $\rightarrow$ competencia judicial internacional del domicilio de la matriz europea

El tribunal neerlandés admitió su competencia para resolver la causa planteada porque la demandada Shell (matriz) tenía su domicilio en los Países Bajos, en aplicación del art. 2 del Reglamento 44/2001 (anterior al Reglamento 1215/2012), que establecía el foro general del domicilio del demandado. En aplicación del artículo 60 del anterior reglamento, la Royal Dutch Shell PLC tiene su domicilio en la ciudad de La Haya, donde tiene su centro de actividad principal, aunque tiene su sede estatutaria en Londres. El Reglamento entonces aplicable y la versión actualizada, permiten que ambos foros (inglés y neerlandés) sean competentes ya que cumplen con el foro general del domicilio del demandado y los criterios de conexión con el domicilio (art. 60, actual 63 RBIbis).

A pesar de admitir la demanda contra la empresa matriz, y que precisamente ello supuso el puente para poder aceptar la demanda contra la filial nigeriana de Shell (vid. ep. III.1), la sentencia, en aplicación del derecho nigeriano, desestimó la demanda contra la matriz Shell (vid. ep. III.9).

Efectivamente, no obstante se haya asumido la competencia, más difícil resultará que dicho tribunal acabe estimando que el daño sufrido en un tercer Estado sea responsabilidad de la matriz.

Así pues, para determinar el instrumento o norma de Derecho internacional privado que establezca el foro competente es necesario distinguir entre la empresa filial y la empresa matriz. Cuando la empresa matriz radica en un Estado miembro de la UE, la norma que prevé que un determinado tribunal de un Estado miembro tiene competencia para conocer un asunto y resolver, es, en primer lugar, el Reglamento UE 1215/2012 (RBIbis). Cuando este Reglamento sea de aplicación desde la perspectiva material (daño extracontractual, materia delictual o cuasidelictual) y temporal (a partir del 10 de enero de 2015), los tribunales de los Estados miembros donde es de aplicación dicho reglamento, utilizarán las normas sobre competen-

${ }^{26}$ Marta Requejo Isidro, «La responsabilidad de las empresas por violación de derechos humanos deficiencias del marco legal», Scientia Juris (2011), 31. https://www.revuegeneraledudroit.eu/wp-content/uploads/scientia01theme_requejo.pdf. Acceso en enero de 2020. Liesbeth F.H. Enneking, «Judicial remedies: The issue of applicable law», en: Human Rights in Business. Removal of Barriers to Access to Justice in the European Union, eds. por Juan José Álvarez Rubio; Katerina Yiannibas, (London \& New York: Routledge, 2017), 43-48. 
cia judicial internacional previstas en su articulado. En concreto, contiene el foro general del domicilio del demandado (art. 4 RBIbis), foro que puede ser utilizado directamente si el demandado (la empresa matriz) tiene el domicilio en un Estado miembro de la UE.

\section{Litigio-ejemplo: Akpan \& Milieudefensie v. Shell Nigeria \& Netherlands $\rightarrow$ competencia judicial internacional de la filial nigeriana}

La empresa Shell se opone en reiteradas ocasiones a que el tribunal del distrito de La Haya, tenga competencia judicial internacional para conocer la causa. En la moción sobre la jurisdicción resuelta en la interlocutoria de 24/02/2010, el tribunal, en aplicación del derecho interno neerlandés, concluye que sí tiene competencia, tanto para la causa contra la matriz como la que es contra la filial, bajo el argumento de que son demandas conectadas entre ellas, y por ello, se resuelven conjuntamente por razones de eficiencia.

La norma jurídica neerlandesa que fundamenta esta decisión es la sección 7, libro 1, del Código procesal civil neerlandés $(D C C P)$ : «Article 7 Jurisdiction over counter actions, joinders and interventions- 1 . If legal proceedings are to be initiated by a writ of summons and a Dutch court has jurisdiction with respect to one of the defendants, then it has jurisdiction as well with respect to the other defendants who are called to the same proceedings, provided that the rights of action against the different defendants are connected with each other in such a way that a joint consideration is justified for reasons of efficiency.» (FJ 4.1).

Shell argumenta de nuevo que Milieudefensie et al. abusaron de las normas procesales al presentar demanda contra la matriz y la filial colectivamente, pero el tribunal desestima dicho argumento. El tribunal arguye que, según el derecho nigeriano (aplicable al fondo del asunto (vid. ep. III.6)), la matriz puede ser responsable por daños por negligencia sufrida por personas como consecuencia de las actividades de la filial (cita Chandler v. Cape) (FJ 4.3).

Destacamos los argumentos del tribunal que justifican que son demandas conectadas entre ella: 1) son demandas con la misma base legal (tort of negligence under Nigerian Law) y 2) la tendencia internacional a responsabilizar a las empresas matrices de multinacionales en su propio país por las prácticas nocivas de sus filiales extranjeras (FJ 4.5).

El tribunal incluso argumenta, que de desestimarse la causa contra la matriz [como finalmente sucede], el tribunal neerlandés continuaría siendo competente bajo la norma de la Sección 7 DCCP, a pesar de que ya no quedaría conexión con la jurisdicción neerlandesa (FJ 4.6) ${ }^{27}$.

${ }^{27}$ Para ampliar el estudio en relación a la competencia judicial internacional de los tribunales de La Haya sobre ambas sociedades, matriz y filial de Shell: Laura García Álvarez, «Daños privados por contaminación en el tráfico externo: a propósito del caso Akpan vs. Shell (Nigeria)», Cuadernos de Derecho Transnacional 5, n. 2 (2013): 558 y ss. Acceso en enero de 2020, https://e-revistas.uc3m.es/index.php/CDT/article/view/1823. 
Este caso, es un ejemplo más de la poca utilidad de los foros contemplados en el Reglamento europeo que se debería utilizar para determinar la competencia judicial de los tribunales de los Estados miembros, tanto la versión anterior, como la actual (R.1215/2012) en la que durante el proceso legislativo de modificación no se aprobó la eliminación de la conexión europea, ni la introducción de un forum necessitatis. Por ello este caso, y tantos otros, justifican la competencia de tribunales de Estados europeos a través de las normas internas o foros residuales.

Foros contemplados en el Reglamento 1215/2012 (RBIbis) que podrían resultar útiles en el presente ámbito de estudio, serían: el foro de la responsabilidad extracontractual del tribunal del lugar donde se haya producido o pueda producirse el hecho dañoso (art. 7.2 RBIbis); acción civil de reparación de daños y perjuicios acumulada a un proceso penal (art. 7.3 RBIbis) ${ }^{28}$; cuando hay pluralidad de demandados ante el domicilio de cualquiera de las partes demandantes (art. 8.1 RBbis) ${ }^{29}$. Sin embargo, aplicar estos foros a la matriz son poco probables. Por ejemplo, en relación al art. 7.2 RBIbis, el daño ocasionado en un tercer Estado - lugar del resultado lesivo - tendría que tener su origen en un Estado miembro - lugar del hecho causal - y ello implica tener que demostrar que el origen causal es la decisión (u omisión) o negligencia de la matriz respecto a las operaciones de su filial.

No es posible, además, aplicar estas normas de competencia judicial internacional cuando la demandada es la filial domiciliada en un tercer Estado, precisamente por no cumplir con el requisito de tener el domicilio en un Estado miembro de la UE (conexión comunitaria) ${ }^{30}$.

Al no poder aplicarse los foros previstos en el Reglamento europeo, deberá recurrirse a las normas residuales de los Estados miembros (art. 6

${ }^{28}$ En cuanto a la acumulación de acción civil por responsabilidad a un proceso penal (art. 7.3 RBIbis) se requiere que la norma procesal del foro lo admita, así es en el derecho español, francés, sueco y croata.

${ }^{29}$ Requiere que todos los demandados tengan el domicilio en un Estado miembro.

${ }^{30}$ Uno de los objetivos de la reforma del RBI (R. 44/2001) era excluir la conexión comunitaria, pero no se logró. Asimismo, tampoco consiguió introducirse foros que habrían favorecido determinar como competentes tribunales de Estados miembros, a través de criterios como la localización del patrimonio del demandado o la actividad de la sociedad demandada, o el foro de necesidad o el forum non conveniens. Para su análisis crítico véase: Daniel Augenstein y Nicola Jägers, «Judicial remedies: The issue of jurisdiction», en: Human Rights in Business. Removal of Barriers to Access to Justice in the European Union, eds. por Juan José Álvarez Rubio; Katerina Yiannibas, (London \& New York: Routledge, 2017) 19-22; Marta Requejo Isidro, «La responsabilidad de las empresas por violación de derechos humanos deficiencias del marco legal», Scientia Juris (2011) 39-43. https://www.revuegeneraledudroit.eu/ wp-content/uploads/scientia01theme_requejo.pdf. Acceso en enero de 2020. 
R.1215/2012). Así las cosas, entran en juego las normas de competencia judicial internacional de las normas internas de los Estados miembros o foros residuales para determinar su propia competencia. Dichas normas estatales abren un abanico de posibilidades diversas con foros que se determinan por: la nacionalidad de las partes (Bélgica, Francia o Luxemburgo), presencia del demandado (Inglaterra, Malta, Finlandia), ubicación de los bienes (Alemania, Polonia, o en Escocia), ubicación de ciertas actividades (Chipre, Polonia, Portugal), domicilio del demandante (Letonia), pluralidad de demandados (Países Bajos), foro de necesidad (Austria, España, Rumanía) ${ }^{31}$. De este modo, entran en juego ciertos foros considerados en general poco razonables, pero que precisamente resultan de utilidad en la materia que nos ocupa $^{32}$. A estos criterios deben añadirse los de tradición anglosajona (la tag jurisdiction o transient jurisdiction - ligada a lograr el trámite de notificación al demandado en un determinado lugar); la doing business jurisdiction - vinculada a la realización regular de actividades con una cierta relevancia en un territorio; el «forum non conveniens» propio del common law, que permite un margen de discrecionalidad al indicar el foro más apropiado (alejándose de la previsibilidad, proximidad y seguridad jurídica). También es largamente contemplado en algunos ordenamientos internos de la UE el foro de necesidad (forum necessitatis) para evitar los casos de denegación de justicia y garantizar la tutela judicial efectiva (art. 6 CEDH), como es en Bélgica, Países Bajos y Francia ${ }^{33}$.

\section{Litigio-ejemplo: Akpan \& Milieudefensie v. Shell Nigeria \& Netherlands $\rightarrow$ acción colectiva y ONG como co-demandante}

El derecho neerlandés admite la demanda colectiva en su Código civil. Nos remitimos al apartado de legitimación de la ONG como co-demandante en que se examina la decisión del tribunal del distrito de La Haya de admitirla como parte actora, a pesar de los argumentos en contra de la empresa Shell (vid. ep. III.4)

En el contexto de las demandas civiles internacionales que analizamos, además del objetivo de que figuren como demandadas tanto la ma-

31 Arnaud Nuyts, 2007 Study on Residual Jurisdiction: General Report, http://ec.europa. eu/ civiljustice/news/docs/study_residual_jurisdiction_en.pdf, y, en el Manual práctico 2016, 64-69.

32 Marta Requejo Isidro, «La responsabilidad de las empresas por violación de derechos humanos deficiencias del marco legal», Scientia Juris (2011) 38. https://www.revuegeneraledudroit.eu/wp-content/uploads/scientia01theme_requejo.pdf. Acceso en enero de 2020.

${ }^{33}$ Un ejemplo destacado fue el caso Akala et al. contra Comilog International S.A, en que el tribunal francés conoció del asunto por ser competente a través del foro de necesidad. Cour d'appel de Paris, 10 septembre 2015. Cour de cassation, civile, Chambre sociale, 28 janvier 2015. 
triz como la filial en el proceso ante el tribunal nacional de un Estado de la UE, también surge el planteamiento de que la parte actora (demandante-víctima) sea múltiple. Ello se conoce como acciones colectivas (class actions), solo aconsejable si la compensación que se reclama es semejante o equiparable entre ellas. De nuevo, la norma aplicable es el Reglamento 1215/2012, y según este las acciones de tipo colectivo dependerán de la ley del país del tribunal que tenga competencia para conocer el litigio; es decir, según el derecho del foro regule la posibilidad o no de múltiples demandantes. Es una posibilidad regulada en algunos ordenamientos internos de la UE en materias específicas, como el consumo, las inversiones o el derecho de la competencia. Señalar que el art. 7.2 del Reglamento 1215/2012 admite el ejercicio de acciones por parte de ONGs o asociaciones de apoyo a víctimas.

\section{Competencia territorial, presentación de la demanda, representación y tasas judiciales}

\section{Litigio-ejemplo: Akpan \& Milieudefensie v. Shell Nigeria \& Netherlands $\rightarrow$ inicio del proceso}

La Royal Dutch Shell PLC tiene dos domicilios: el de Londres (Reino Unido), donde tiene su sede estatutaria, y el domicilio del lugar del centro principal de actividad, en La Haya (Den Haag, Países Bajos). En la sentencia estudiada, si fuera de aplicación el RBIbis (R.1215/2012), el domicilio viene determinado por el art. 63, que establece estos dos criterios para determinar la competencia judicial internacional, que, en el caso, podría haber sido propuesta ante los tribunales ingleses, o los neerlandeses como finalmente se optó. Distinta es la competencia territorial, es decir, cuál tribunal concreto de la jurisdicción neerlandesa resuelve el asunto. En el supuesto es competente el tribunal del distrito de La Haya, ya que territorialmente es dónde tiene su domicilio el demandado, y conoce causas de un importe superior a $25.000 €$. La distribución de las poblaciones en jurisdicciones está prevista en la Ley de clasificación judicial (Wet op de rechterlijke indeling).

El contenido de la demanda viene determinado por la legislación neerlandesa por ser el derecho procesal aplicable (art 10:3 Book 10 DCC). En el proceso a instancia de parte, la demanda se presenta directamente ante la secretaría judicial y contiene la correcta identificación de las partes, la descripción de la solicitud y los motivos en los que se fundamenta, incluidos los motivos para la competencia local del órgano jurisdiccional e identificación del representante profesional de la abogacía.

Efectivamente, en los Países Bajos, el principio jurídico es que las partes deben estar representadas por un abogado/a en los asuntos civiles y mercantiles, 
y en los litigios en que conoce el tribunal de un Distrito es necesaria la representación legal. En este asunto el agricultor nigeriano y la ONG están representados por el bufete de abogados Prakken d'Oliveira Human Rights Lawyers (Ámsterdam), en concreto, por la letrada Channa Samkalden.

Para presentar la demanda se tuvieron que pagar tasas al tribunal del distrito de La Haya. Las tasas exigidas dependen de la naturaleza y cuantía del litigio previsto en la ley de tasas en los procedimientos civiles (Wet tarieven in burgerlijke zaken). En la justicia neerlandesa también intervienen profesionales de la oficina judicial en los asuntos civiles al inicio del proceso que realiza las notificaciones (dagvaarding) y, posteriormente, interviene en la ejecución de la sentencia ${ }^{34}$.

El tribunal territorialmente competente viene determinado por las normas internas de cada Estado. Los criterios habitualmente utilizados para ello son: el domicilio o residencia habitual del demandado o el lugar en el que el demandado tenga sus bienes. También hay legislaciones que permiten presentar el escrito de inicio del procedimiento ante cualquier tribunal (Inglaterra y Gales). La admisión a trámite de una demanda civil o del inicio del proceso depende del cumplimiento de requisitos formales que fija la legislación del tribunal que conoce del litigio. En la mayoría de Estados miembros de la UE una demanda de responsabilidad civil por daños requiere que sea presentada por escrito, y cada ordenamiento establece qué información debe incluirse, como sería: la identificación de las partes, la cuantía reclamada, la fecha del daño, etc. Añadir que en alguna legislación se prevé la presentación de un formulario para iniciar un procedimiento y otros ordenamientos aceptan la presentación por vía telemática.

En la mayoría de legislaciones de los Estados miembros de la UE se exige el pago de tasas judiciales para iniciar un procedimiento judicial, es decir, hacer uso del servicio público de las administraciones de justicia, aunque en Luxemburgo, por ejemplo, no se prevea una tasa inicial en ámbito civil; o en Finlandia se distinga entre la tasa judicial y la documental. La cuantía de las tasas depende de varios factores, como del montante de la demanda, el tipo de litigio o la materia objeto de controversia (por ejemplo, se elimina cuando hay menores), o una mezcla de criterios. Generalmente, el hecho de que sea un procedimiento transnacional no encarece la tasa. El momento de pago de la tasa, varía de ordenamiento a ordenamiento, pudiendo ser, cuando se interpone la demanda, cuando se

${ }^{34}$ El precio por las notificaciones ex oficio realizadas por el agente (bailiff) está fijado por ley. Una notificación de demanda, tenía un coste de 72€ en 2010. Mark L. Tuil, «The Netherlands», en The Costs and Funding of Civil Litigation. A comparative Perspective, eds. por Christopher Hodges et al., (Oxford, Portland, Oregon: Hart publishing, 2010), 411. 
archiva o cuando se resuelve. La cuantía es muy variada y puede ir de un euro a miles de euros ${ }^{35}$.

Las legislaciones de los Estados miembros de la UE requieren de la intervención de un profesional de la abogacía (letrado, attorney, solicitor, avocat, rechtsanwalt, avvocato) para el desarrollo del procedimiento, aunque puede no ser necesario, dependiendo de la materia y de la cuantía de la reclamación. En algunas legislaciones, se regula la intervención de otros profesionales en los procedimientos judiciales. Por ejemplo, en España se contempla la figura del procurador, cuya función es la de representación, mientras que en otros ordenamientos intervienen profesionales para realizar las notificaciones, para levantar actas o para ejecutar la sentencia (bailiffs, hussier de justice).

\section{Lengua del proceso judicial}

\section{Litigio-ejemplo: Akpan \& Milieudefensie v. Shell Nigeria \& Netherlands $\rightarrow$ lengua del proceso}

La lengua oficial en los Países Bajos es el neerlandés, y en la provincia de Frisa también el frisón. El escrito de demanda y los documentos anexos se tienen que presentar en la lengua oficial (neerlandés) aunque en la sentencia estudiada se comprueba que el tribunal aceptó documentos en inglés, así por ejemplo: Informe de 25 de junio de 2009 firmado por el Clean Up Supervisor del gobierno de Nigeria; Declaración de los representantes de la comunidad de Ikot Ada Udo (Delta de Nigeria) de 17 de mayo de 2012; Informe de Mr. Kuprewicz of Accufacts Inn de 3 de septiembre de 2012 encargado por Milieudefensie. Otros documentos, como informes periciales, sí figuraban en neerlandés.

Asimismo, destacar que, en relación al derecho aplicable al supuesto, que era el nigeriano, éste figura redactado en inglés y se fundamenta en el common law (vid. ep. III.6). El tribunal neerlandés utilizó y citó directamente en inglés las leyes nigerianas como la OPA (Oil Pipelines Act 1956); y aplicó jurisprudencia del common law de Inglaterra leída también en inglés, por ejemplo, el caso Chandler v Cape. Además, utiliza los términos «Tort of negligence and duty of care» a lo largo de la resolución (p.ej., FJ 4.23, 4.26, 4.35).

Consideramos que es destacable la utilización del inglés por parte del tribunal, a pesar de que obviamente la lengua vehicular fue el neerlandés. El dominio del inglés por parte de la población neerlandesa, y en particular de los operadores jurídicos, fue un factor favorable en este proceso teniendo

35 Costas procesales, E-Justicia: https://e-justice.europa.eu/content_costs_of_proceedings-37-es.do; Christopher Hodges et al., eds., The Costs and Funding of Civil Litigation. A comparative Perspective (Hart publishing, Oxford, Portland, Oregon, 2010), 114-131. 
en cuenta que el inglés es la lengua oficial en Nigeria (aunque tiene más de quinientas lenguas no oficiales). El conocimiento de la lengua extranjera facilitó el contacto entre los agricultores y sus representantes legales, pero, además, supuso el ahorro de algunas traducciones, coste que es notable en procesos transnacionales $^{36}$.

Todos los escritos aportados durante un proceso deben estar en la lengua oficial del foro competente (Francia, Alemania) o cualquiera de ellas cuando son varias las oficiales (España, Bélgica) para ser aceptados por los tribunales. En los supuestos transnacionales es habitual tener que traducir la documentación y, en su caso, las declaraciones de testimonios o peritos tendrán que ser interpretadas por traductor en la lengua oficial del tribunal. En derecho comparado de la UE existe la posibilidad que el operador jurídico (p.ej. notariado) utilice otras lenguas cuando las conocen bien, asimismo, hay legislaciones que también permiten investigar el derecho extranjero motu proprio (p.ej. derecho español). Sin embargo, no es habitual aceptar documentos en otras lenguas (más allá de certificados estándares multilingües o formularios dinámicos de la UE).

\section{Capacidad para ser parte (legitimación procesal), la legitimación (material) y subrogación: el papel de las ONGs}

\section{Litigio-ejemplo: Akpan \& Milieudefensie v. Shell Nigeria \& Netherlands $\rightarrow$ legitimación del señor Akpan}

Las demandadas Shell et al. están en desacuerdo sobre la legitimación del Sr. Akpan para ser parte actora en la causa de reclamación por daños.

Por su parte, las demandantes prueban que el Sr. Akpan es el poseedor de las tierras y estanques que explota de modo agrario y pesca, dado que en aplicación de la ley nigeriana del common law, si la usa y la cultiva es posesión. Fue presentada como prueba la declaración de la comunidad de Ikot Ada Udo que indicaba que los terrenos eran usados por el Sr. Akpan. Este documento se aportó en inglés. (FJ 4.16,17; 2.12)

Comprobamos que se mezcla la norma procesal neerlandesa sobre la legitimación con el derecho material nigeriano, que también es de aplicación para justificar la legitimación material como titular del derecho de reparación del daño sufrido.

${ }^{36}$ Los honorarios fijados por el Ministerio de Justicia neerlandés, en cuanto a las traducciones del inglés es de 0.79 euros/línea y, respecto a los intérpretes es de 43.89 euros/hora más desplazamientos, en su caso. 
Las víctimas extranjeras que han sufrido el daño tienen que disponer de capacidad para ser parte en el momento de presentar la demanda, es decir, capacidad para ser titular de derechos y deberes en un proceso judicial, asimismo, capacidad para comparecer y realizar válidamente actos procesales. Como cuestión procesal, cada tribunal aplica su derecho procesal (lex fori regit processum) y dispone cuál será la ley utilizada para determinar si se dispone de capacidad.

Más complejo en estos asuntos es determinar la legitimación (material) para intervenir en un proceso, requisito también procesal de modo que depende de la ley procesal del foro, pero vinculada al derecho material aplicable al asunto, ya que es esta última la que determina en cada caso quiénes pueden ser demandantes y demandados en un proceso según la titularidad del objeto litigioso (el daño sufrido). Se distingue, por un lado, la legitimación directa, de modo que se es titular de la relación jurídica, o en el ámbito de responsabilidad extracontractual, quien ha sufrido el daño (víctima). Por otro lado, la legitimación indirecta (o por substitución), es decir si cabe la posibilidad que una persona que no ha sufrido el daño directamente tiene igualmente interés legítimo para ser parte actora en la demanda. Cada legislación puede ser más o menos restrictiva en cuanto a las personas legitimadas, de modo que establezcan si está legitimada solo la víctima (por interés legítimo) o también establezcan como legitimados otras personas (también personas jurídicas) no titulares de la relación jurídica o interés legítimo.

Concretamente, en ámbito de la responsabilidad por daños, en aplicación del Reglamento Roma II (R. 864/2007) ${ }^{37}$, cuando el foro competente sea el de un Estado miembro de la UE, el cual determina la ley aplicable a la obligación extracontractual, también establece que será dicha ley sustantiva aplicable la que determinará las personas que tienen derecho a la reparación del daño sufrido personalmente (art. 15.f RRII). Esta sería la legitimación directa de la víctima, ya que tiene un interés legítimo en que sea resarcido el daño.

\section{Litigio-ejemplo: Akpan \& Milieudefensie v. Shell Nigeria \& Netherlands $\rightarrow$ legitimación de la ONG como actora}

La ONG Milieudefensie disponía de legitimación para ser parte actora en la demanda contra Shell (filial y matriz) como codemandante, junto a los agricultores según el tribunal neerlandés. Este aplica la Sección 3:305a, del título 3.11, del Libro 3 del Dutch Civil Code (DCC), sobre las acciones

37 Reglamento (CE) 864/2007 del Parlamento europeo y del Consejo de 11 de julio de 2007 relativo a la ley aplicable a las obligaciones extracontractuales (Roma II), DOUE 31.7.2007. 
colectivas (class actions) ${ }^{38}$. En su primer apartado indica que: una fundación o asociación con plena capacidad jurídica que, según sus estatutos, tiene por objeto la protección de intereses específicos, puede presentar demanda judicial que pretenda proteger intereses similares de otras personas (en el caso, las pretensiones del agricultor).

Shell et al. arguyen como inadmisible las demandas de la ONG, porque el Código civil utilizado es neerlandés cuando el derecho sustantivo aplicable en el caso es el derecho nigeriano y, este, no reconoce ningún tipo de acción colectiva.

El tribunal del distrito de La Haya responde que la sección 3:305a $D D C$ es una norma de derecho procesal aplicable al supuesto, cuestión resuelta en la interlocutoria del mismo tribunal de distrito de 14.9.2011 ${ }^{39}$. (FJ 4.11)

Shell et al. también argumentan que Milieudefensie no desarrolla suficientes actividades para proteger el medio ambiente en Nigeria, y que los intereses de las reclamaciones son individuales y puramente locales.

El tribunal rechaza el argumento y sostiene que varias reclamaciones de la ONG son supraindividuales, porque del mandato de descontaminación del suelo, la limpieza de los estanques y la elaboración de planes de contingencia, se beneficiaría no solo el Sr. Akpan sino también el resto de la comunidad y el medio ambiente de ese territorio. Todo ello responde a la actividad objetiva que Milieudefensie desarrolla en la promoción de los intereses ambientales en Nigeria, y que figura en sus estatutos de promover la protección de medio ambiente a nivel mundial. (FJ 4.12-13)

Las asociaciones o fundaciones que denuncian las violaciones de derechos humanos cometidos por empresas transnacionales, las ONGs, juegan un papel esencial cuando se presenta una demanda judicial contra las empresas multinacionales. Existen ONGs nacionales del país donde se ha cometido el daño que pueden representar a las víctimas concretas o intereses colectivos generales en un proceso interno. Estas mismas ONGs, con interés legítimo, devienen extranjeras cuando sea competente un tribunal de otro Estado. Es por ello que previamente debe determinarse su capacidad para ser parte según el derecho procesal del foro, y para ello debe reconocerse su personalidad jurídica otorgada por el derecho de otro Estado a esa entidad extranjera $^{40}$. Ante dichas dificultades, puede recomendarse la participación de una ONG con sede en el país del tribunal del Estado miembro que

38 Desde 1994 las asociaciones y las fundaciones (verenigngen y stichtingen) están legitimadas para presentar demandas que tengan por objeto los intereses de un grupo de personas con intereses similares. Mark L. Tuil, «The Netherlands», en The Costs and Funding of Civil Litigation. A comparative Perspective, eds. por Christopher Hodges et al., (Oxford, Portland, Oregon: Hart publishing, 2010), 409.

39 ECLI:NL:RBSGR:2011:BU3529

40 Es el derecho procesal del tribunal que conoce el asunto el que determina la capacidad procesal y la exigencia de requisitos para ser titular de derechos y deberes procesales de las personas físicas o jurídicas, por lo general, cuando ostentan personalidad jurídica según su derecho nacional, de su domicilio, residencia habitual o sede. 
conozca del asunto, como sucede en el caso, en la que interviene como codemandante Milieudefensie. Los argumentos de su intervención no solo es la economía procesal, sino porque esta gozará de capacidad para ser parte, ya que se le reconoce la personalidad jurídica. Superada esta cuestión previa (reconocimiento de la capacidad procesal), resultará de gran complejidad determinar si la ONG «europea» ostenta de legitimación material.

En cuanto a la legitimación indirecta, ello es, establecer otros legitimados además de la víctima titular del derecho, dependerá de la ley sustantiva aplicable para determinar si lo están. Esta legitimación indirecta nos interesa para los supuestos que presentamos. La víctima del daño, legitimada para ser parte, puede convenir con una ONG que se subrogue de modo que pueda ejercer una acción procesal en nombre propio y como parte. Esta posibilidad de transmisibilidad del derecho a reclamar suele regirse por la ley de la relación jurídica afectada ${ }^{41}$. En concreto, en las reclamaciones extracontractuales, el Reglamento Roma II (R. 864/2007) determina que la ley aplicable al supuesto será la que establecerá la posibilidad de la transmisibilidad del derecho a reclamar por los daños o solicitar indemnización (art. 15.e RRII).

En estos supuestos, la ONG podrá optar por actuar de distinta forma. Por un lado, como legitimada en una acción colectiva, para ello el derecho sustantivo aplicable (determinado por el Reglamento Roma II (R. 864/2007) cuando el foro competente sea de un Estado miembro de la UE) establecerá cómo acreditar su condición de representante de las víctimas legitimadas para ser demandantes. Por otro lado, cuando el bien protegido sea difuso (el territorio, el medio ambiente), podría ostentar de legitimación extraordinaria en que su fundamento sea la protección del interés general y su objetivo sea el cese de las actividades dañosas ${ }^{42}$. De esta segunda posibilidad contamos con un ejemplo reciente (abril de 2019) que merecerá seguir su evolución. En concreto, siete ONGs junto con centenares de codemandantes particulares han demandado a Shell por negligencia en las actuaciones de la empresa por no evitar los daños medioambientales que está generando en el mundo ${ }^{43}$.

${ }^{41}$ Pilar Jiménez Blanco, El proceso civil transfronterizo, (Madrid: Col. Abogacía internacional, 2016), Vol. IV, 55.

${ }^{42}$ Para ampliar el estudio sobre la legitimación y las acciones colectivas, véase: Laura García Álvarez, Daños ambientales transnacionales y acceso a la justicia (Madrid: Dykinson, 2016), 69-226.

${ }^{43}$ En abril de 2019, la ONG Milieudefensie y otras 6 ONGs, junto a unos 400 codemandantes, demandaron civilmente a Shell ante los tribunales neerlandeses, no por un daño concreto, sino bajo el argumento de negligencia en las actuaciones de la empresa porque no evita daños que, según la legislación aplicable, en su caso la de los Países Bajos, le obliga a cum- 


\section{Plazos de caducidad y/o prescripción}

\section{Litigio-ejemplo: Akpan \& Milieudefensie v. Shell Nigeria \& Netherlands $\rightarrow$ derecho aplicable a la prescripción de la acción}

La demanda contra Shell se presentó en 2008 y los daños en el Delta de Nigeria sucedieron en 2006 y 2007. Podría plantearse si la acción había prescrito, para ello, debemos saber qué derecho determinará el tiempo de prescripción.

El tribunal del distrito de La Haya utiliza sus normas de derecho internacional privado para determinar si considera la cuestión de la prescripción como sustantiva o procesal. El art. 10:14 de su Código civil [se aplica dicha norma ya que el Reglamento Roma II (R. 864/2007) aún no era de aplicación en la fecha] establece que la prescripción y la existencia de derecho de acción se determina por el derecho aplicable a la relación jurídica, de modo que a la prescripción fue aplicable el derecho sustantivo nigeriano (vid. ep. III.6).

Para los derechos continentales la prescripción o la caducidad son cuestiones sustantivas, así se aplica el derecho material aplicable al litigio (sea el del foro o una ley de otro Estado). En otros sistemas jurídicos la caducidad o la prescripción son cuestiones procesales, como sucede en el common law, de modo que se rigen por las normas procesales del tribunal que conoce el asunto.

Añadimos la norma de origen europeo, el Reglamento Roma II (R. 864/2007), la cual dispone que será la ley aplicable al fondo (la determinada por las normas de conflicto del mismo reglamento) la que se aplicará para determinar el inicio, interrupción y suspensión de los plazos de prescripción y caducidad (art.15.h RRII).

Conocer qué ley se aplicará repercute en la cuestión tan importante como es el plazo de caducidad o prescripción. Los plazos previstos en las

plir con el objetivo de la prevención del cambio climático (objetivos de París). Los demandantes exigen que «Shell comience a reducir inmediatamente sus emisiones de $\mathrm{CO} 2$ al menos al $45 \%$ para 2030 (respecto de 2010) y al cero neto en 2050». De no cumplir con la ley, la negligencia supone un acto ilícito. Los argumentos jurídicos se inspiraron en el caso Fundación Urgenda $v$. Reino de los Países Bajos, en que los demandantes acusaron el gobierno neerlandés de violar su deber de protección a la sociedad según la sección 6:162 del código de Derecho civil de los Países Bajos. De este modo, el gobierno tiene la obligación legal de evitar las emisiones. Los demandantes exigieron que el gobierno neerlandés tomase más medidas para reducir las emisiones de efecto invernadero en los Países Bajos, incluso para asegurar que las emisiones neerlandesas en el año 2020 sean al menos un 25\% más bajas que las de 1990 . https://en.milieudefensie.nl/climate-case-shell/friends-of-the-earth-netherlands-sues-shell-forcausing-climate-change. Acceso en enero de 2020. 
legislaciones de los Estados miembros no están unificados y varían según la materia en litigio. Por ejemplo, en España el plazo general es de 5 años, mientras que en Italia es de 6 años, en los Países Bajos de 20 años o en Inglaterra y Gales son 6 años. Sin embargo, se establecen plazos particulares en materia de daños extracontractuales, que pueden resultar más reducidos, como en España 1 año, en Italia 5 años al igual que en los Países Bajos, pero en Luxemburgo son 30 años ${ }^{44}$.

\section{Ley aplicable al fondo}

\section{Litigio-ejemplo: Akpan \& Milieudefensie v. Shell Nigeria \& Netherlands $\rightarrow$ Ley aplicable}

En el caso, no se utilizó el Reglamento Roma II (R. 864/2007) para determinar la ley aplicable porque no era de aplicación temporal en el momento en que sucedieron los hechos generadores de los daños (art. $31 \mathrm{y}$ 32 RRII). Consecuentemente, se aplicó la norma neerlandesa sobre conflicto de leyes en materia de tort (Wet Conflictenrecht Onrechtmatige Daad; $W C O D)$. En aplicación de la Sección 3 (1) y (2) WCOD, las demandas se debían sustentar con la ley nigeriana, en concreto, la del Estado de Akwa Ibom, por ser el lugar donde ocurrió el daño y causó sus efectos nocivos. (FJ 4.8-10).

En la sentencia neerlandesa se comprueba como el tribunal aplica el derecho nigeriano, en concreto, la Nigerian Oil Pipelines Act 1956, y también, el derecho inglés y su jurisprudencia, que es la que se utiliza para dilucidar si había o no un deber de control (duty of care) de la empresa petrolera respecto a sus instalaciones por el que resultó el daño causado a la demandante. Finalmente, es el derecho utilizado por el tribunal para eximir de responsabilidad a la matriz. (vid. ep. III.8)

En el supuesto hipotético de que el Reglamento Roma II (R. 864/2007) hubiera sido de aplicación temporal, entonces, siguiendo la norma general se debería aplicar el derecho nigeriano, con lo cual, la misma solución que aporta el derecho internacional privado neerlandés. Ahora bien, el Reglamento Roma II (R. 864/2007) hubiera podido dar otra solución y determinar como aplicable el derecho neerlandés, atendiendo a las disposiciones específicas para daños medioambientales (art. 7 RRII). Para ello, la demandante hubiera teniendo que demostrar (difícil) que las acciones u omisiones de la empresa matiz domiciliada en los Países Bajos fueron la causa de los daños ambientales. De admitir la causalidad, se

${ }^{44}$ Rosa María García Pérez, «La prescripción en el derecho europeo», en: Sixto Sánchez Lorenzo, coord.., Derecho contractual comparado: una perspectiva europea y transnacional, (Thomson Reuters Aranzadi, 2013), 1727-1760. 
podría haber aplicado la ley del Estado del hecho generador del daño, en este caso la ley de los Países Bajos ${ }^{45}$. Las diferencias de aplicar un derecho $\mathrm{u}$ otro son notables, téngase en cuenta que dicha ley es la que determina cuestiones tan importantes como el alcance de la responsabilidad, la determinación de las personas que puedan considerarse responsables por sus actos, las medidas para garantizar el cese y la reparación, causas de exoneración, la evaluación de los daños o la indemnización solicitada, entre otras (art. 15 RRII).

Una vez determinada la competencia del tribunal y la legitimación de la parte actora/s, es necesario fundamentar la demanda en un derecho sustantivo que dé repuesta a la pretensión de la víctima. Este derecho material, en un litigio transfronterizo, tiene que ser previamente determinado para poder ser alegado en los escritos judiciales de las partes y, posteriormente, aplicado por el tribunal para fundamentar la resolución.

El instrumento normativo aplicable para determinar la ley aplicable a la responsabilidad civil por daños no contractuales cuando conoce del asunto un tribunal de un Estado miembro de la UE, será el Reglamento Roma II (R. 864/2007) ${ }^{46}$, a partir del 11 de enero de 2009 (art. 32 RRII) y con carácter universal (art. 3 RRII) es decir, que la ley designada puede ser la de cualquier país, respecto las materias no excluidas ${ }^{47}$.

La norma general prevista en el Reglamento Roma II (R. 864/2007) es que será de aplicación la ley del país en que se haya producido el daño, con independencia del país donde se haya producido el hecho generador del daño y cualquiera que sea el país(es) en que se producen las consecuencias indirectas del hecho (art. 4 RRII). Así, en los supuestos objeto del presente estudio, en muchas ocasiones la ley aplicable será la del país donde la filial ha producido el daño (lex loci delicti commissi); de modo que el tribunal de un Estado miembro aplicará un derecho extranjero en su foro (Vid. ep. III.6).

Esta norma general tiene varias excepciones, así, se aplicará preferentemente la ley elegida por las partes en determinadas circunstancias (art. 14 RRII), o bien, puede ser aplicable una norma concreta sobre ilíci-

45 Manual práctico 2016, p. 73

${ }^{46}$ Para su análisis detallado véase: Liesbeth Enneking, «Judicial remedies: The issue of applicable law», en: Human Rights in Business. Removal of Barriers to Access to Justice in the European Union, eds. por Juan José Álvarez Rubio; Katerina Yiannibas, (London \& New York: Routledge, 2017), 49-65.

47 Cuando el objeto del daño a la víctima esté vinculado a un contrato laboral, entonces será de aplicación para determinar la ley aplicable el Reglamento 593/2008 (RRI). El Reglamento 864/2007, asimismo tiene un listado amplio de materias excluidas de su aplicación en ámbito de extracontractuales (art. 1.2). 
tos específicos, de entre los cuales destacamos la norma de conflicto sobre daños medioambientales (art. 7 RRII). Este último artículo permite a la víctima del daño ambiental, elegir entre la ley del país donde se produce el daño o la ley del país en el cual se produjo el hecho generador del daño.

\section{Prueba del derecho extranjero}

\section{Litigio-ejemplo: Akpan \& Milieudefensie v. Shell Nigeria \& Netherlands $\rightarrow$ prueba del derecho extranjero}

Según el Código civil neerlandés, las normas de derecho internacional privado y la ley designada por éstas serán aplicadas ex officio (art. 10:2 $D C C$ ). Así pues, si la norma de conflicto neerlandesa designó como aplicable el derecho nigeriano (ley extranjera), este, imperativamente será de aplicación por parte del tribunal.

En los Países Bajos, el derecho extranjero que sea de aplicación ante sus tribunales, debe ser probado por las partes, aunque el tribunal también puede obtener información a través de convenios Internacionales o solicitando un informe de un experto al Instituto Jurídico Internacional (International Juridisch Instituut) ${ }^{48}$ o investigando por sí mismo.

En el litigio contra Shell, el tribunal utiliza un Informe del International Juridisch Instituut, e investiga motu proprio el common law inglés dado que el derecho nigeriano forma parte del common law basado en el derecho de Inglaterra (FJ 4.10). En concreto, analiza los casos Rylands v Fletcher, Chandler v. Cape, Capar PLC, Industries plc v. Dickman (1990), Smith v. Littlewoods (1987). Para probar el derecho nigeriano-common law, ambas partes aportan dictámenes jurídicos (FJ 4.10)

Cuando la lex causae resulte ser una ley extranjera a la del foro que conozca el asunto, esta deberá ser aplicada como si de su propio derecho se tratara. Pero obviamente, los operadores de los tribunales y la judicatura no tienen la obligación de conocer dicho derecho extranjero como sí lo tienen de su propio derecho (iura novit curia). Cómo debe conocerse dicho derecho extranjero y ser aplicado es una cuestión no resuelta por el Derecho de la UE, a pesar de contar con varios Reglamentos europeos que determinan

48 International Juridisch Instituut, situado también en La Haya (https://www.iji.nl/en). Para un informe de la $I J I$, la tarifa es de $175 €$ /hora sin IVA. Las tarifas de expertos extranjeros también se contabilizan. Para los informes en los litigios donde se dispone de asistencia jurídica gratuita, la tarifa es de $44 €$ /hora sin IVA, solo las 6 primeras horas se facturan al solicitante, ya que las restantes son reembolsados por el Ministerio de Seguridad y Justicia. 
la ley aplicable (como el Reglamento Roma II). Atendiendo a cada ordenamiento jurídico el trato previsto para el derecho extranjero es diverso en relación a la carga de la prueba, los medios de prueba admitidos o si su aplicación es imperativa, ex officio o facultativa ${ }^{49}$. Así, por ejemplo, en España y en Francia el derecho extranjero debe ser probado por las partes, mientras que en Alemania y Grecia los jueces tienen la obligación de investigar el derecho extranjero o solicitar informe a un experto. La consecuencia de la falta de la prueba también varía, a modo de ejemplo, se opta por aplicar el derecho propio (lex fori) solo cuando las partes podían escoger el derecho aplicable (Francia), de forma excepcional (España) o como último recurso

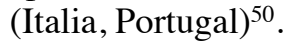

\section{La carga y aportación de pruebas y su valor probatorio}

\section{Litigio-ejemplo: Akpan \& Milieudefensie v. Shell Nigeria \& Netherlands $\rightarrow$ carga de la prueba}

En el caso, el derecho procesal neerlandés (Wetboek van Burgerlijke Rechtsvordering) establece como norma general que la carga de la prueba recae en quien afirma el hecho, aunque el tribunal puede requerir pruebas de la otra parte (arts. 149-207 WBR). El derecho internacional privado neerlandés, sin embargo, establece que la ley aplicable a la relación jurídica o hecho se aplicará también cuando contenga reglas para la distribución de la carga de la prueba (art. 10:13 DCC). Es decir, a pesar de que la carga de la prueba es una cuestión esencialmente procesal, en los asuntos internacionales también es de aplicación el derecho sustantivo que se aplica en la resolución del litigio.

Durante el proceso, los demandantes (agricultor y ONG) reiteran ante el tribunal la petición para que la empresa aporte documentación sobre el mantenimiento de los conductos del petróleo, y Shell no la aporta. En la sentencia examinada (30.1.2013), el tribunal desestima de nuevo el requerimiento tal y como había establecido en una interlocutoria anterior (14.09.2011) (FJ 4.61). El tribunal realiza una interpretación restrictiva del artículo 843a del Código civil neerlandés, de manera que, si la parte actora no prueba suficientemente el interés determinante en obtener un documento

49 Véase: Maria Font i Mas, «La aplicación del derecho extranjero resultante de la remisión de las normas de conflicto europeas en el contexto de los sistemas imperativos sui generis como el español o el facultativo inglés», en Práctica de la prueba del derecho extranjero, dir. por Joan Picó i Junoy (Madrid: La Ley, 2011), 44-74.

50 Clemens Trautmann, «Foreign Law. Aplication. Ascertainment» en: The Max Planck Encyclopedia of European Private Law, ed. por Jürgen Basedow et al, (Oxford University Press, 2013), 711-719. 
concreto, no se estima su «legítimo interés»y, por tanto, será denegada su petición ${ }^{51}$.

La demandante reclama de nuevo al tribunal la aportación de documentación a Shell, en concreto, sobre el control de la matriz respecto a la filial nigeriana, y el tribunal, de nuevo, deniega la petición (10.9.2013).

La ONG obtiene información sobre Shell a través de otro proceso judicial también contra la misma multinacional petrolera que se desarrolla ante el tribunal inglés y por daños sucedidos en Nigeria. Con esta nueva información, requiere de nuevo documentación sobre el estado de los conductos del petróleo en el Delta de Nigeria, la cual revelaría el conocimiento de su estado por parte de la matriz (12.03.2015). El tribunal ordena a Shell permitir el acceso a todos los documentos relacionados con el caso $(18.12 .2015)^{52}$. Shell envía documentación a la parte actora, pero Miliudefensie indica que ésta es parcial, Shell responde a ello que parte de la documentación está perdida $(11.10 .2016)^{53}$.

En este tipo de litigios, mucha de la información necesaria está en posesión de las empresas, las cuáles, como partes demandadas, no tienen la obligación de probar los hechos y pueden evitar su presentación, o bien, presentar parcialmente la documentación, como argucia procesal.

La aportación de pruebas por parte de los demandantes (agricultores y ONG) fue realmente difícil, situando las partes en plena desigualdad al no disponer de la misma información ${ }^{54}$.

El derecho procesal del tribunal competente para resolver el litigio, es el que determina la admisibilidad de los medios de prueba (documental, pericial, testifical), su fuerza probatoria, el procedimiento probatorio y el aseguramiento de pruebas. En relación a qué pruebas son requeridas o sobre quién recae la carga de la prueba, puede venir regido por la ley sustantiva aplicable en determinadas materias, opción prevista en el Reglamento Roma II (R. 864/2007) sobre obligaciones extracontractuales (art. 22 RRII).

${ }^{51}$ Laura García Álvarez, «Daños privados por contaminación en el tráfico externo: a propósito del caso Akpan vs. Shell (Nigeria)», Cuadernos de Derecho Transnacional 5, n. 2 (2013): 577. Acceso en enero de 2020, https://e-revistas.uc3m.es/index.php/CDT/article/ view/1823.

52 Court of Appeal The Hague 17 December 2015, ECLI: NL: GHDHA: 2015: 3586 (Dooh/Shell); Court of Appeal The Hague 17 December 2015, ECLI: NL: GHDHA: 2015: 3587 (Shell/Akpan); Court of Appeal The Hague 17 December 2015, ECLI:NL:GHDHA:2015:3588 (Oguru-Efanga/Shell). Véase el comentario de Cees van Dam, «Preliminary judgments Dutch Court of appeal in the Shell Nigeria case», 14th January 2016. Acceso en enero de 2020. http://www .ceesvandam.info/default.asp?fileid=643.

53 Acceso en enero de 2020, www.milieudefensie.nl.

${ }^{54}$ Liesbeth Enneking se muestra critica con el sistema neerlandés de aportación de pruebas y de valoración, situación que considera que vulnera el art. 6 CEDH. Liesbeth F.H. Enneking, «Multinationals and Transparency in Foreign Direct Liability Cases», The Dovenschmidt Quarterly, n. ${ }^{\circ}$ 3(2013), 137-141; 146. 
A pesar de esta norma europea, en los ordenamientos internos de los Estados miembros, como norma general, se determina que la carga de la prueba recae en los demandantes (parte actora). Ahora bien, en ámbito de derechos humanos y empresa, no son pocas las voces que reclaman una inversión de esta norma ya que los demandantes son la parte débil en el litigio. De hecho, en algunos ordenamientos, como en los Países Bajos o Francia, existe una tendencia a invertir la carga de la prueba o modificarla ligeramente en algunas materias sobre responsabilidad, a favor de la víctima ${ }^{55}$.

\section{Litigio-ejemplo: Akpan \& Milieudefensie v. Shell Nigeria \& Netherlands $\rightarrow$ aportación de pruebas y valor probatorio}

Para resolver el litigio en estudio es importante determinar la causa del derrame de petróleo, ya que, si se determina que hubo sabotaje, la ley nigeriana prevé que la empresa no es responsable por el daño causado por el derrame. Shell et al. demuestran mediante pruebas que fue fácil cerrar las válvulas abiertas causantes del derrame con una llave inglesa. La demandante no aportó ninguna prueba que cerciorarse que podría haber otras causas distintas al sabotaje. (FJ 4.18-21 e Interlocutoria de 14 de septiembre de 2011).

En los Países Bajos, el tribunal es libre de evaluar las pruebas presentadas, excepto si la ley determina el contrario. Presentamos como ejemplo de la dificultad de probar y determinar su valor probatorio, el supuesto concreto en que la demandante pretendía demostrar la insuficiencia de medios de limpieza utilizados por la empresa en la zona afectada por los derrames del petróleo. El tribunal desestimó su pretensión porque no consiguieron probar que el método utilizado fue inadecuado. En concreto, la limpieza fue certificada por autoridades nigerianas a través del informe RENA: Remediaton by Enhanced Natural Attenuation through land faming process (FJ 2.8 y 9). La ONG alegó que los certificados nacionales nigerianos eran poco de fiar, pero el tribunal neerlandés no entró a valorar esta cuestión, sino que se centró en el contenido del documento (FJ 4.48, 49 y 50).

En este tipo de procesos es esencial probar dos cuestiones, por un lado, como se ha comprobado, la vinculación entre la empresa matriz y la filial para poder levantar el velo y demostrar la «business unit» ${ }^{56}$. Y, por otro lado, resulta esencial para resolver el litigio en materia de daños extracontractuales aportar documentales que prueben las causas de los

55 Rapport donnant suite au postulat 14.3663 CPE-E du 26 novembre 2014, «Entreprises et droit de l'home: analyse comparée des mesures judiciaires et non judiciares offrant un accés à la réparation», Berne, 14.09.2018, 6 .

56 José Elías Esteve Moltó, «The impunity veil of transnational corporations: the judicial saga of Bhopal», en: Empresas y Derechos humanos, coord. por Maria Chiara Marullo y Francisco Javier Zamora Cabot (Nápoles: Ed. Scientifica srl, 2018), 274-275. 
daños y los efectos, con el fin de demostrar los daños sufridos y poder reclamar responsabilidad (indemnización) y, en su caso, cese de las acciones dañosas. Para ambas cuestiones es necesario el acceso a documentación que evidencie tales extremos, y la parte actora no siempre tiene acceso a dichas evidencias.

Así de crítico se muestra un artículo de Amnistía Internacional sobre la resolución del tribunal neerlandés de 2013: «Todos los demandantes se encontraron con la tarea prácticamente imposible de demostrar sus alegaciones. (...) el tribunal holandés tuvo que depender de los informes de la investigación de los vertidos de petróleo elaborados por la propia Shell. La investigación llevada a cabo por Amnistía Internacional ha revelado serias deficiencias en el proceso de investigación de los vertidos de petróleo en Nigeria. (...) A lo largo de toda la sentencia queda patente que los agricultores sencillamente no tuvieron acceso a la información y los conocimientos necesarios para refutar las afirmaciones de Shell.»57

\section{Sentencia, apelación y ejecución forzosa}

\section{Litigio-ejemplo: Akpan \& Milieudefensie v. Shell Nigeria \& Netherlands $\rightarrow$ sentencia y apelación}

La sentencia del tribunal del distrito de La Haya de 30 de enero de 2013, dictamina:

- En relación a la empresa matriz neerlandesa: el desistimiento de las reclamaciones contra la empresa Shell en aplicación del derecho nigeriano y la jurisprudencia inglesa (vid. ep. III.6), en especial, en el examen de la aplicabilidad del «duty of care» respecto a las instalaciones que causan un daño provocado por terceros. El tribunal neerlandés excluye la responsabilidad de la matriz de ese control, a pesar de tener como política de empresa la prevención de daños medioambientales por sus actividades; también se excluye, por falta de proximidad entre la matriz y los habitantes de la zona afectada, de modo que no sería aplicable como precedente el caso Chandler v. Cape PLC; tampoco sería aplicable porque el negocio no es exactamente el mismo, ya que la matriz formula las líneas de política general y participa en la estrategia mundial y la gestión de riesgos mientras que la filial produce el petróleo. Tampoco se acepta como argumento que la matriz debiera

57 Audrey Gaughran, «La contaminación causada por Shell en el Delta del Níger: lo bueno, lo malo y la búsqueda incesante de la justicia», Amnistía Internacional, 1.02.2013, acceso en enero de 2020, https://www.amnesty.org/es/latest/campaigns/2013/02/shell-s-nigerdelta-pollution-the-good-the-bad-and-the-ongoing-quest-for-justice. 
conocer mejor los riesgos específicos de la industria filial que opera en Nigeria.

- La sentencia dictamina en relación a la filial nigeriana: por un lado, la desestimación de las reclamaciones contra la filial nigeriana por daños causados a Milieudefensie. Esta ONG situada en Ámsterdam, a pesar de estar legitimada por el derecho procesal neerlandés (vid. ep. III.4), no ha sufrido los daños en Nigeria, por lo tanto, no lo ampara la ley nigeriana (ni la neerlandesa), por falta de proximidad. Por otro lado, la desestimación de la responsabilidad de la filial nigeriana por los daños causados al Sr. Akpan por los derrames de petróleo en 2006 y 2007 porque fueron causados por sabotaje de terceros, y según la norma nigeriana $O P A$, es causa de excepción de la obligación de pagar indemnización si sufre daños cualquier persona como consecuencia de cualquier rotura o fuga de la tubería (Sección 11 (5) (c) OPA). Distinto sería que la causa fuera que la filial nigeriana respondió inadecuadamente del derrame de petróleo o las consecuencias de la limpieza inapropiada.

Sin embargo, el tribunal, sí que estima que hay responsabilidad por negligencia de la filial nigeriana, porque sí tenía un deber específico de cuidado «duty of care» con respecto a las personas que viven en las cercanías del pozo petrolero y especialmente pescadores y agricultores, como el Sr. Akpan. La sentencia establece que era razonablemente exigible a la empresa que se hubiesen tomado medidas de seguridad contra el sabotaje, que era previsible y creó una situación peligrosa a los habitantes de la zona. Ello conduce a estimar una compensación económica para el Sr. Akpan de la empresa nigeriana.

La sentencia fue apelada por ambas partes $(1.05 .2013)^{58}$ y aun no hay resolución.

El proceso se está dilatando en el tiempo: la duración de un proceso interno ante un tribunal de distrito se estima de media entre 1.5 y 2 años. El litigio-ejemplo, tuvo una duración de 4 años y 7 meses desde la presentación de la demanda (9.5.2008) hasta la fecha de la sentencia (30.1.2013). La dilación en el proceso se debe, en parte, por las continuas interposiciones de recursos de la empresa Shell respecto la competencia del tribunal, así como la negativa reiterada de aportar información que reclamaba insistentemente la demandante. Por otro parte, por las circunstancias propias de ser un litigio transnacional. Sea como fuere, la duración del proceso afecta económicamente y conlleva desgaste personal (o social) a ambas partes, pero no tienen parangón.

58 En el portal de la ONG explica los distintos pasos de la apelación, como por ejemplo, la reclamación de documentación a Shell, o como, de nuevo, la empresa impugna la competencia del tribunal neerlandés. A día de hoy, aun no hay sentencia: https://en.milieudefensie. nl/shell-in-nigeria/timeline-the-course-of-the-lawsuit, acceso el enero de 2020. 
Los litigios internacionales se dilatan en el tiempo, pero terminan. Puede finirse el litigio antes de obtener una resolución judicial a través de un acuerdo entre las partes, una transacción, o bien, acabar con una sentencia judicial, si bien esta puede ser apelada. Y, aún puede transcurrir mucho más tiempo cuando la sentencia deba ejecutarse internacionalmente.

\section{Litigio-ejemplo: Akpan \& Milieudefensie v. Shell Nigeria \& Netherlands $\rightarrow$ hipótesis de ejecución forzosa}

Si la sentencia de la apelación condenara a la matriz de Shell domiciliada en los Países Bajos, su ejecución sería sencilla procesalmente porque se aplicaría el propio derecho procesal ya que no sería una sentencia extranjera.

En cambio, si la sentencia neerlandesa tuviese que ejecutarse en Nigeria, se tendrían que accionar las normas de cooperación jurídica internacional, en concreto, el sistema de ejecución de sentencias extranjeras previsto en la legislación nigeriana a falta de convenio internacional aplicable.

En Nigeria ha habido un aumento de peticiones de ejecución de sentencias extranjeras en materia comercial entre el 2005 y el $2015^{59}$. Según A. Yekini, existirían dos métodos de reconocimiento y ejecución de sentencias extranjeras, la «common law action» que implica un nuevo procedimiento (sin revisar el fondo) que es largo y con altos costes de litigio, y el «statutary registration» que debe realizarse en un plazo de 12 meses desde la petición. Este último sistema se fundamenta en la reciprocidad prevista en las Acts inglesas (1922 y 1961) aunque de la doctrina del Tribunal Supremo de Nigeria se aparta de su aplicación literal y las aplica de forma liberal y pragmática. Según el autor, de la jurisprudencia del alto tribunal nigeriano se desprende que no es necesaria la reciprocidad, de manera que se reconocerían las sentencias extranjeras cuando no incumpliesen alguno de los motivos de no ejecución, que son: la falta de jurisdicción del tribunal extranjero, falta de notificación, fraude y orden público; estos dos últimos motivos son poco utilizados en la práctica jurisprudencial.

Para nuestro litigio-ejemplo, merece mencionar que podría ser o no motivo de denegación de ejecución de una eventual sentencia neerlandesa a través de la «statutary registration», la falta de competencia del tribunal extranjero (tribunal del distrito de La Haya), dado que según el derecho nigeriano se fundamentaría en que el deudor (a quien debe ejecutarse la sentencia) tenía la residencia en ese país extranjero en el momento de realizarse la acción contra él. No obstante, incluye particularidades, como

59 Nigeria es un Estado federal en el que los tribunales que tienen competencia de registrar las sentencias extranjeras son: State High Courts, Federal High, National Industrial Court. Abubakri Yekini, «Foreign judgments in Nigerian courts in the last decade: a dawn of liberalization», Nederlands Internationaal Privaatrecht (NIPR), n 2 (2017), 204. 
el supuesto en que la sociedad mercantil tenga su sede principal o el lugar donde se mantiene una filial, siempre que sea más adecuado en relación con la actividad de esa filial. Para ello, se requieren pruebas evidentes que demuestren que la matriz controla y dirige los negocios de la filial (Adams v. Cape Industries Plc (1990) 2 WLR 657) ${ }^{60}$.

De nuevo, sería necesario demostrar la vinculación de la empresa matriz y la filial «business unit» y el deber de vigilancia.

Superada, en su caso, la apelación, si la sentencia fuera condenatoria a la empresa (p.ej. indemnizar, tomar medidas para resarcir el daño, cesar la causa del daño) debería iniciarse un nuevo procedimiento de ejecución. La ejecución internacional deviene complicada según el país donde deba desprender efectos ejecutivos cuando no exista un convenio internacional entre los Estados parte, de modo que el proceso de ejecución, que puede requerir la obtención de una previa declaración judicial de ejecutividad (exequatur), alargando de nuevo el proceso. Además, existe la posibilidad que según el derecho del Estado de recepción de la sentencia extranjera puede hallarse algún argumento o condición para no homologar dicha sentencia en su país.

\section{Costes del litigio, costas, asistencia jurídica gratuita}

\section{Litigio-ejemplo: Akpan \& Milieudefensie v. Shell Nigeria \& Netherlands $\rightarrow$ costas}

En el presente estudio no se ha conseguido conocer los costes de todo el proceso, pero indudablemente han sido enormes.

En cuanto a las costas, la normativa neerlandesa sigue la regla general de que quien pierde el litigio paga el proceso, bajo el concepto de «billijkheid» que se traduce como «fairnes» en inglés, de modo que los costes de la parte vencedora son compensados, incluidos los honorarios de los peritos expertos (art. 237.1 DCCP ${ }^{61}$. Se prevén legislativamente excepciones en ámbito de familia, en que cada parte carga con sus gastos (art. 327 DCCP). También existe la posibilidad de que el juez ordene a

${ }^{60}$ Abubakri Yekini, «Foreign judgments in Nigerian courts in the last decade: a dawn of liberalization», Nederlands Internationaal Privaatrecht (NIPR), n 2 (2017), 205-218.

61 «The policy objective that is being served is the objective of access to justice. In serving this objective, the interests of two parties are weighed against each other, on the one hand, the interest of a party that has prevailed in litigation and wants to recover his or her costs on the other hand, the interest of a party with an arguable claim who should not be deterred from instigating his claim». Mark L. Tuil, «The Netherlands», en The Costs and Funding of Civil Litigation. A comparative Perspective, eds. por Christopher Hodges et al., (Oxford, Portland, Oregon: Hart publishing, 2010), 405. 
cada parte sufragar sus propios gastos si ambas partes han ganado y perdido distintas pretensiones en el caso.

Este último supuesto es el que el tribunal del distrito de La Haya decide aplicar en cuanto a las costas, de modo de que cada parte cargue con sus propias costas del proceso (FJ 4.62)

Son diversos los costes que se generan en un proceso judicial, y estos se multiplican cuando el litigio es internacional. A continuación, un listado no exhaustivo de los costes comunes en un proceso de derecho privado: tasas judiciales, honorarios de abogacía y otros profesionales jurídicos cuando la legislación procesal del foro lo requiera, honorarios de los peritos expertos, gastos de los testigos, costas judiciales, pago de impuestos, obtención de pruebas, servicio de ejecución a través de profesionales, y, en ocasiones, depósito preventivo de gastos. A este elenco, debe añadirse los gastos específicos de los litigios transfronterizos: coste de la traducción de la documentación (pruebas y derecho extranjero) y del servicio de interpretación para las vistas orales, certificación o prueba del derecho extranjero, legalización o apostilla de los documentos públicos que se aporten, cooperación de autoridades judiciales, nuevo procedimiento en caso de ejecución forzosa transnacional.

\section{Litigio-ejemplo: Akpan \& Milieudefensie v. Shell Nigeria \& Netherlands $\rightarrow$ asistencia jurídica gratuita}

En el presente estudio no se ha conseguido conocer si los demandantes han obtenido asistencia jurídica gratuita, aunque pensamos que esta es insuficiente para cubrir los gastos de un proceso internacional de estas características.

En derecho neerlandés se encuentra regulado en la Ley de asistencia jurídica gratuita (Wet op de rechtsbijstand), la cual tiene fundamento constitucional (art. 18.2). Los solicitantes pueden ser tanto personas físicas como jurídicas, en cualquier rama del derecho. La norma prevé su concesión a residentes, así que no cubriría a los agricultores, pero sí a la ONG, aunque esta última tendría que demostrar la insuficiencia de recursos económicos.

Efectivamente, en algunos ordenamientos la asistencia jurídica gratuita es solo para las personas residentes o nacionales del foro, ello excluye a los demandantes extranjeros en los casos de responsabilidad transnacional directa $^{62}$. En el supuesto de que efectivamente la víctima demandante fuera beneficiaria de dicha asistencia jurídica gratuita, tendría que examinarse

${ }^{62}$ Liesbeth Enneking, «Judicial remedies: The issue of applicable law», en: Human Rights in Business. Removal of Barriers to Access to Justice in the European Union, eds. por Juan José Álvarez Rubio; Katerina Yiannibas, (London \& New York: Routledge, 2017), 68. 
previamente qué cubriría la ayuda teniendo en cuenta que es un litigio transnacional y qué consecuencias económicas supondría perder el litigio.

Los recursos económicos necesarios para iniciar un costoso y duradero proceso internacional es una premisa que condiciona sin lugar a dudas la posibilidad de acceso a la justicia. La tutela judicial efectiva debe garantizar la asistencia jurídica gratuita con el fin de garantizar el acceso al proceso como demandante (y, en su caso como demandado) a aquellos quienes no tengan suficientes recursos. A pesar de que garantizar la tutela judicial efectiva y un proceso equitativo, conllevaría correlativamente la asistencia jurídica gratuita de forma universal (art. 6.1 CEDH y art. 47 CDFUE), lo cierto es que hay limitaciones de acceso a esa asistencia por razón de extranjería.

\section{Reflexiones finales}

Demandar civilmente a las empresas multinacionales por daños causados a las personas o a la tierra, aunque no sea la solución, tal y como señalábamos al inicio, sí puede considerarse un paso hacia adelante para combatir la violación de derechos humanos por parte de las empresas. De superar el largo y costoso proceso judicial y conseguir una sentencia condenatoria de la empresa, para la víctima supone una compensación económica, y en el mejor de los casos un cese de la violación o abuso; pero no compensa en absoluto perder la tierra, el hogar, los medios de subsistencia, la salud o la propia vida. Para las víctimas indirectas, estas somos la sociedad en general cuando los daños son sobre todo medioambientales, una sentencia condenatoria puede suponer el cese del daño (p.ej. contaminación) y la recuperación del espacio natural, aunque solo sea parcialmente.

Efectivamente, si los litigios terminan con una sentencia condenatoria pueden suponer un motivo disuasorio de violación de derechos humanos y un mandato para que las multinacionales tengan una posición activa y vinculante de control de las actividades de sus filiales. Así lo valora Milieudefensie en el caso que hemos presentado: «Si estos cuatro agricultores finalmente ganan sus casos, se espera que conduzcan a más casos. Pero no es probable una avalancha de casos. Lleva mucho tiempo y es muy costoso llevar a una gran compañía petrolera a los tribunales. Esperamos especialmente que Shell y otras compañías petroleras sean más cuidadosas y hagan un mayor esfuerzo para evitar daños a las personas y al medio ambiente, porque saben que podrían ser llevados a los tribunales en Europa.» ${ }^{63}$

${ }^{63}$ La traducción es nuestra. Acceso en enero de 2020, https://en.milieudefensie.nl/shellin-nigeria/frequently-asked-questions. 
Merece destacar el aumento de causas civiles abiertas contra empresas, según el Informe de Responsabilidad Legal Empresarial 2018: «Sube la temperatura: rendición de cuentas empresarial por el cambio climático» del Centro de Información sobre Empresas y Derechos Humanos ${ }^{64}$. Se rastrearon 14 demandas sólo en el sector de combustibles fósiles en todo el mundo (demandas climáticas) a principios de 2018. Ciertamente cada día aumentan el número de demandas civiles por responsabilidad de las empresas multinacionales, a pesar que solo hace unos pocos años parecía insuperable el primer obstáculo jurídico que era la asunción de la competencia de los tribunales del domicilio de las matrices por hechos acaecidos en terceros Estados perpetrados por sus filiales. No obstante los pequeños avances, los datos indican que son pocos los litigios contra empresas sitas en la UE que resuelven considerando responsable a las multinacionales, siendo la mayoría de causas desestimadas, a menudo por falta de pruebas suficientes para justificar las reclamaciones, o bien, son resueltas fuera de los tribunales ${ }^{65}$.

Del litigio-ejemplo que hemos ido desglosando pueden realizarse distintas valoraciones de las que destacaremos solo dos. La primera, es que los obstáculos jurídicos en estos litigios transnacionales evidencian la desigualdad económica y procesal de las partes siendo imprescindible el apoyo de las ONGs europeas. La segunda, que la traba procesal más evidente, a nuestro entender, se centra en la carga de la prueba que recae en la parte actora, víctima y titular del derecho a proteger, que resulta ser parte débil en el proceso.

Si bien puede afirmarse que la víctima tiene acceso a la justicia en términos generales, este acceso no goza de garantías cuando debe obtener pruebas, que generalmente están en posesión de la empresa demandada, con el objetivo de probar cuestiones esenciales en el proceso y que de su no presentación suponen el desistimiento de la pretensión. Por una parte, deviene básico probar la vinculación entre la empresa matriz con la filial, del que derivan la competencia del tribunal del Estado de la matriz para demandar a la filial, así como, la posible responsabilidad de la matriz por los daños. Y, por otra parte, es esencial la prueba de los daños sufridos en sí mismos, que suponen la legitimación en el proceso.

En aras de garantizar el derecho fundamental de acceso a la justicia, en concreto, a un proceso equitativo y a la tutela judicial efectiva (art. 6 CEDH y art. 47 CDFUE), resulta imprescindible legislar con el fin de eli-

${ }^{64}$ Acceso en enero de 2020, https://www.business-humanrights.org/sites/default/files/ Spanish_ES_FINAL.pdf.

${ }^{65}$ Liesbeth Enneking, «Judicial remedies: The issue of applicable law», en: Human Rights in Business. Removal of Barriers to Access to Justice in the European Union, eds. por Juan José Álvarez Rubio; Katerina Yiannibas, (London \& New York: Routledge, 2017), 41-42. 
minar el desequilibrio procesal entre las partes. Ello ya fue apuntado en los Principios Rectores de la ONU (26) ${ }^{66}$ y deviene un Objetivo de Desarrollo Sostenible $(16)^{67}$. En este sentido, veamos cómo evolucionan las legislaciones de los Estados miembros de la UE y las medidas que promocionan las políticas de la Unión Europea en la consecución de la Agenda 2030, en especial, en la promoción de los principios de responsabilidad de las empresas y derechos humanos ${ }^{68}$. En concreto, a través del nuevo «Plan de Acción de la UE sobre derechos humanos y democracia para 2020-2024», en el que se prevé «promover el derecho a un juicio imparcial a fin de garantizar el respeto de los derechos humanos en la administración de justicia. Mejorar el acceso a la justicia y a la asistencia jurídica, incluida la asistencia jurídica gratuita, $(\ldots) »^{69}$.

Como indicábamos el acceso a los tribunales es posible, aunque no fácil, a través de foros residuales (el legislador europeo tendría que incluir como mínimo un foro de necesidad); pero la competencia judicial internacional de un tribunal de un Estado miembro de la UE no garantiza, a pesar de la neutralidad de los tribunales, que el desequilibrio existente entre las partes no afecte en la consecución de un proceso equitativo, como se ha observado en el ejemplo. En futuras modificaciones legislativas de las normas procesales internas de los Estados, sería deseable considerar a los titulares de los derechos de resarcimiento por daños por violaciones de derechos humanos, como parte débil en el proceso, y atribuirles prerrogativas particulares de protección como se prevé, por ejemplo, al consumidor. La inversión

${ }^{66}$ En los principios operativos, en materia de «mecanismos juiciales estatales», núm. 26 «Los Estados deben adoptar las medidas apropiadas para asegurar la eficacia de los mecanismos judiciales nacionales cuando aborden las violaciones de derechos humanos relacionadas con empresas, en particular considerando la forma de limitar los obstáculos legales, prácticos y de otros tipos que puedan conducir a una denegación del acceso a los mecanismos de reparación.»

67 ODS 16: Paz, Justicia e Instituciones Sólidas, en concreto la meta: 16.3 Promover el estado de derecho en los planos nacional e internacional y garantizar la igualdad de acceso a la justicia para todos.

68 «(...) Tanto en su actuación interior como exterior, la UE tendrá que seguir promoviendo la aplicación de las directrices y los principios acordados internacionalmente sobre conducta empresarial responsable, como los Principios rectores de las Naciones Unidas sobre las empresas y los derechos humanos. Este aspecto también es importante para garantizar la igualdad de condiciones a nivel internacional.» Comisión Europea: «Documento de reflexión. Hacia una Europa sostenible en 2030», COM (2019) 22, (30.1.2019), 26.

69 Comunicación conjunta al Parlamento europeo y al Consejo, Comisión europea, Join (2020) 5 final, Bruselas, 25/3/2020. En su anexo, p.5. El nuevo plan establece cinco líneas de actuación, una de las cuales es «promover un sistema mundial de derechos humanos y democracia», en la que figura «E) Sector empresarial», indicando como una de las acciones la de reforzar el compromiso a la aplicación de los principios rectores, en particular mediante planes de acción nacionales y directrices pertinentes sobre diligencia debida, inter alia. 
de la carga de la prueba podría ser una buena medida procesal a considerar; así como la posibilidad de obtener el beneficio de justicia gratuita a pesar de ser extranjero residente en un tercer Estado cuando el demandado sea una empresa sita en el Estado del foro. Veremos durante los próximos años la aplicación de la Agenda 2030 en la UE y si sus políticas legislativas en esta materia se dirigen en la dirección propuesta.

\section{Sobre la autora}

Maria Font-Mas es Doctora en derecho con mención internacional en la Universidad de Barcelona (UB). Es profesora agregada (contratada doctor) y responsable del área de Derecho internacional privado de la Universitat Rovira i Virgili (URV). Ha realizado estancias de investigación en varias universidades e institutos, destacando el Instituto Suizo de Derecho Comparado. Sus líneas de investigación engloban la circulación de los documentos públicos extranjeros; la coherencia jurídico-lingüística de las traducciones de los Reglamentos europeos de Derecho internacional privado; las empresas de economía social en el derecho europeo (ahora también plataformas virtuales); derechos humanos y empresas. Sus últimos artículos son: Multilingualism in EU Private International Law Regulations: the Chimera of Vertical and Horizontal Coherence? J. Forner \& A. Santos (eds.), Coherence of the Scope of Application. EU Private International Legal Instruments, ISDC, Geneva/Zurich 2020, Schulthess Editions Romandes, pp. 43-68; «Plataformas de Capital versus Plataformas Sociales en la Economía Colaborativa: Punto de vista jurídico internacional», (CIRIEC 2018/12); «Human Rights in European Union. A practical handbook for civil society organisations and Human Rights defenders», A. Pigrau et al., Civil Justice Programme of the European Union, (September 2016.); (Dir): El documento público extranjero en España y en la Unión Europea. Estudios sobre las características y efectos del documento público. (Bosch Editor, 2014). Dirige la Clínica Jurídica-Aprendizaje Servicio del Master en derecho de la empresa y la contratación. Es secretaria del Departamento de Derecho privado, procesal y financiero (URV).

\section{About the author}

Maria Font-Mas is a PhD in Law (international mention) at the University of Barcelona. Senior Lecturer of Private International Law at Universitat Rovira i Virgili (URV-Tarragona). Main areas of teaching and research are in Private International Law. Visiting researcher at Institut Suisse 
de Droit Comparé, University of Aberdeen, University of Lyon, University of Torino, University of Nijmegen, University McGill (Canada). Her main work-lines cover areas such as foreign authentic acts's circulation and effects; linguistic and legal coherence of European PIL Regulations's translations; Business \& Human Rights; Social enterprises in European Law (now, digital platforms). Her last works are: Multilingualism in EU Private International Law Regulations: the Chimera of Vertical and Horizontal Coherence? J. Forner \& A. Santos (eds.), Coherence of the Scope of Application. EU Private International Legal Instruments, ISDC, Geneva/Zurich 2020, Schulthess Editions Romandes, pp. 43-68; «Plataformas de Capital versus Plataformas Sociales en la Economía Colaborativa: Punto de vista jurídico internacional», (CIRIEC 2018/12); «Human Rights in European Union. A practical handbook for civil society organisations and Human Rights defenders», A. Pigrau et al., Civil Justice Programme of the European Union, (September 2016.); (Dir): El documento público extranjero en España y en la Unión Europea. Estudios sobre las características y efectos del documento público. (Bosch Editor, 2014). She is the coordinator of the Legal Clinic-Service Learning in the University Master's Degree in Business and Contractual Law (URV). Secretary of the Department of Private, Procedural \& Financial Law. 


\section{Derechos de autor}

Los derechos de autor (para la distribución, comunicación pública, reproducción e inclusión en bases de datos de indexación y repositorios institucionales) de esta publicación (Cuadernos Europeos de Deusto, CED) pertenecen a la editorial Universidad de Deusto. El acceso al contenido digital de cualquier número de Cuadernos Europeos de Deusto es gratuito inmediatamente después de su publicación. Los trabajos podrán leerse, descargarse, copiar y difundir en cualquier medio sin fines comerciales y según lo previsto por la ley; sin la previa autorización de la Editorial (Universidad de Deusto) o el autor. Así mismo, los trabajos editados en CED pueden ser publicados con posterioridad en otros medios o revistas, siempre que el autor indique con claridad y en la primera nota a pie de página que el trabajo se publicó por primera vez en CED, con indicación del número, año, páginas y DOI (si procede). Cualquier otro uso de su contenido en cualquier medio o formato, ahora conocido o desarrollado en el futuro, requiere el permiso previo por escrito del titular de los derechos de autor.

\section{Copyright}

Copyright (for distribution, public communication, reproduction and inclusion in indexation databases and institutional repositories) of this publication (Cuadernos Europeos de Deusto, CED) belongs to the publisher University of Deusto. Access to the digital content of any Issue of Cuadernos Europeos de Deusto is free upon its publication. The content can be read, downloaded, copied, and distributed freely in any medium only for non-commercial purposes and in accordance with any applicable copyright legislation, without prior permission from the copyright holder (University of Deusto) or the author. Thus, the content of CED can be subsequently published in other media or journals, as long as the author clearly indicates in the first footnote that the work was published in CED for the first time, indicating the Issue number, year, pages, and DOI (if applicable). Any other use of its content in any medium or format, now known or developed in the future, requires prior written permission of the copyright holder. 